\title{
Developments in Landsat Land Cover Classification Methods: A Review
}

\author{
Darius Phiri * and Justin Morgenroth \\ New Zealand School of Forestry, University of Canterbury, Christchurch 8140, New Zealand; \\ justin.morgenroth@canterbury.ac.nz \\ * Correspondence: darius.phiri@pg.canterbury.ac.nz; Tel.: +64-22-621-4280
}

Received: 1 August 2017; Accepted: 13 September 2017; Published: 19 September 2017

\begin{abstract}
Land cover classification of Landsat images is one of the most important applications developed from Earth observation satellites. The last four decades were marked by different developments in land cover classification methods of Landsat images. This paper reviews the developments in land cover classification methods for Landsat images from the 1970s to date and highlights key ways to optimize analysis of Landsat images in order to attain the desired results. This review suggests that the development of land cover classification methods grew alongside the launches of a new series of Landsat sensors and advancements in computer science. Most classification methods were initially developed in the 1970s and 1980s; however, many advancements in specific classifiers and algorithms have occurred in the last decade. The first methods of land cover classification to be applied to Landsat images were visual analyses in the early 1970s, followed by unsupervised and supervised pixel-based classification methods using maximum likelihood, K-means and Iterative Self-Organizing Data Analysis Technique (ISODAT) classifiers. After 1980, other methods such as sub-pixel, knowledge-based, contextual-based, object-based image analysis (OBIA) and hybrid approaches became common in land cover classification. Attaining the best classification results with Landsat images demands particular attention to the specifications of each classification method such as selecting the right training samples, choosing the appropriate segmentation scale for OBIA, pre-processing calibration, choosing the right classifier and using suitable Landsat images. All these classification methods applied on Landsat images have strengths and limitations. Most studies have reported the superior performance of OBIA on different landscapes such as agricultural areas, forests, urban settlements and wetlands; however, OBIA has challenges such as selecting the optimal segmentation scale, which can result in over or under segmentation, and the low spatial resolution of Landsat images. Other classification methods have the potential to produce accurate classification results when appropriate procedures are followed. More research is needed on the application of hybrid classifiers as they are considered more complex methods for land cover classification.
\end{abstract}

Keywords: Landsat; land cover; classification methods; remote sensing; OBIA; pixel-based

\section{Introduction}

The launch of the Earth Resource Technology Satellite (ERTS) 1, later called Landsat 1 in July 1972, has contributed significantly to the development of remote sensing applications such as land cover classification [1,2]. The main aim of the Landsat satellite program was to provide a tool for continuous monitoring of Earth's resources $[1,3,4]$. With the Landsat program running for over four decades now, different methods for classifying land cover were developed. The development of these methods was largely attributed to the improvements in Landsat images, advancement of computer technology, development of geographic information systems (GIS) and the Landsat free access policy $[5,6]$.

Land cover classification using Landsat images has evolved over the last four decades. Land cover is the physical substance covering the Earth's surface, for example forests, water and grasslands [7]. 
Thus, land cover classification involves the discrimination of land cover types through different classification methods which were developed in the field of remote sensing [8,9]. The launch of new satellites with high spatial, spectral, temporal and radiometric resolution, and increasing knowledge in the field of information technology were the major advancement in the development of contemporary land cover classification methods. Land cover classification methods using Landsat images originated from early aerial photo interpretation methods which were common in the 1950s and 1960s [10,11]. During this period, land cover was classified based on visible image properties such as texture, color, shape and compactness $[12,13]$. The visual image analysis was done on printed images from which, boundaries of different land cover types were delineated and represented with different symbols.

Improvements in computer software and hardware have contributed significantly to the development of image interpretation methods through the development of pattern recognition techniques [5]. The introduction of numeric-based pattern recognition algorithms was a major breakthrough in land cover classification and it is the basis of modern classification methods $[5,6]$. The last four decades have seen the development of land cover classification such as pixel-based, knowledge-based, object-based and many other classification algorithms highlighted in this review. Furthermore, the change in the Landsat data access policy from a commercial to a free access approach in 2008 and the advent of high performance computing capabilities have led to wider applications of these remote sensing classification methods to Landsat images [4,14-16].

Since the launch of the first satellite, Landsat 1, in 1972, the Landsat program has launched seven other satellites, six of these satellites were successfully launched, with the objectives of maintaining continuity of the Earth's monitoring mission and developing improvements to the sensors $[4,17$, 18]. The Landsat program provides four types of images (Table 1): Multispectral Scanner (MSS) by Landsat 1, 2 and 3; Thematic Mappers (TM) by Landsat 4 and 5, which also provided MSS images; Enhanced Thematic Mappers (ETM+) by Landsat 7; and Observation Land Images (OLI) provided by Landsat 8 [18]. Landsat MSS, TM, ETM+ and OLI have all been used in land cover classification using different methods of land cover classification $[9,19]$. In order to maintain continuity in the provision of Landsat data, Landsat 9 will be launched in 2023 with improved qualities [4].

Research on land cover classification methods based on Landsat images has been an important topic over the past four decades, especially with the current effects of climate change [20-22]. While many review articles covered topics related to Landsat and land cover classification $[9,14,15,19]$; there is no review of the development of Landsat land cover classification methods. In this review, we address the major developments in land cover classification methods based on Landsat images by looking at: (1) the major trends in the development of classification methods; and (2) the methods suitable for specific land cover types. The first part of this paper (Section 2) presents the overview of the Landsat program. Section 3 focuses on the actual classification methods by reporting the developments, accuracy, strengths and limitations of these methods. Finally, we make recommendations for optimal ways to use Landsat images in land cover classification in Sections 4-6. 
Table 1. Summary of different types of Landsat images indicating spatial, temporal, radiometric and spectral resolution.

\begin{tabular}{|c|c|c|c|c|c|c|c|c|c|c|c|c|c|c|}
\hline \multicolumn{3}{|c|}{$\begin{array}{c}\text { Landsat 1-3 (MSS) }^{1} \\
1972-1983\end{array}$} & \multicolumn{3}{|c|}{$\begin{array}{c}\text { Landsat 4-5 (MSS) } \\
1975-2013\end{array}$} & \multicolumn{3}{|c|}{$\begin{array}{c}\text { Landsat 4-5 (TM) } \\
1975-2013\end{array}$} & \multicolumn{3}{|c|}{$\begin{array}{l}\text { Landsat } 7 \text { (ETM+) } \\
1999 \text { to Present }\end{array}$} & \multicolumn{3}{|c|}{$\begin{array}{l}\text { Landsat } 8 \text { (OLI) } \\
2013 \text { to Present }\end{array}$} \\
\hline \multirow{2}{*}{$\begin{array}{c}\begin{array}{c}\text { Temporal } \\
18 \text { days }\end{array} \\
\text { Band Name }\end{array}$} & \multicolumn{2}{|c|}{$\begin{array}{c}\text { Radiometric } \\
6 \text { bits }\end{array}$} & \multirow{2}{*}{$\begin{array}{c}\begin{array}{c}\text { Temporal } \\
18 \text { days }\end{array} \\
\text { Band Name }\end{array}$} & \multicolumn{2}{|c|}{$\begin{array}{c}\text { Radiometric } \\
6 \text { bits }\end{array}$} & \multirow{2}{*}{$\begin{array}{c}\begin{array}{c}\text { Temporal } \\
16 \text { days }\end{array} \\
\text { Band Name }\end{array}$} & \multicolumn{2}{|c|}{$\begin{array}{c}\text { Radiometric } \\
8 \text { bits }\end{array}$} & \multicolumn{2}{|c|}{$\begin{array}{cc}\text { Temporal } \\
16 \text { days }\end{array}$} & $\begin{array}{l}\text { Radiometric } \\
9 \text { bits }\end{array}$ & \multirow{2}{*}{$\begin{array}{c}\begin{array}{c}\text { Temporal } \\
16 \text { days }\end{array} \\
\text { Band Name }\end{array}$} & \multicolumn{2}{|c|}{$\begin{array}{c}\text { Radiometric } \\
12 \text { bits }\end{array}$} \\
\hline & $\begin{array}{c}\text { Spectral } \\
(\mu \mathrm{m})\end{array}$ & $\begin{array}{c}\text { Spatial } \\
(\mathrm{m})\end{array}$ & & $\begin{array}{c}\text { Spectral } \\
(\mu \mathrm{m})\end{array}$ & $\begin{array}{c}\text { Spatial } \\
\text { (m) }\end{array}$ & & $\begin{array}{l}\text { Spectral } \\
(\mu \mathrm{m})\end{array}$ & $\begin{array}{c}\text { Spatial } \\
(\mathrm{m})\end{array}$ & Band Name & $\begin{array}{c}\text { Spectral } \\
(\mu \mathrm{m})\end{array}$ & $\begin{array}{c}\text { Spatial } \\
(\mathrm{m})\end{array}$ & & $\begin{array}{c}\text { Spectral } \\
(\mu \mathrm{m})\end{array}$ & $\begin{array}{c}\text { Spatial } \\
(\mathrm{m})\end{array}$ \\
\hline Band 4-Green & $0.5-0.6$ & 60 & Band 4-Green & $0.5-0.6$ & 60 & Band 1-Blue & $0.45-0.52$ & 30 & Band 1-Blue & $0.45-0.52$ & 30 & Band 1-Ultra & $0.43-0.45$ & 30 \\
\hline Band 5-Red & $0.6-0.7$ & 60 & Band 5-Red & $0.6-0.7$ & 60 & Band 2-Green & $0.52-0.60$ & 30 & Band 2-Green & $0.52-0.60$ & 30 & Band 2-Blue & $0.45-0.51$ & 30 \\
\hline Band 6-NIR & $0.7-0.8$ & 60 & Band 6-NIR & $0.7-0.8$ & 60 & Band 3-Red & $0.63-0.69$ & 30 & Band 3-Red & $0.63-0.69$ & 30 & Band 3-Green & $0.53-0.59$ & 30 \\
\hline \multirow[t]{8}{*}{ Band 7-NIR } & $0.8-1.10$ & 60 & Band 7-NIR & $0.8-1.10$ & 60 & Band 4-NIR & $0.76-0.90$ & 30 & Band 4-NIR & $0.77-0.90$ & 30 & Band 4-Red & $0.64-0.67$ & 30 \\
\hline & & & & & & & & & & & & Band 5-NIR & $0.85-0.88$ & 30 \\
\hline & & & & & & & $1.55-1.75$ & 30 & Band 5-SWIR1 & $1.55-1.75$ & 30 & Band 6-SWIR1 & $1.57-1.65$ & 30 \\
\hline & & & & & & Band 7-SWIR2 & $2.08-2.35$ & 30 & Band 7-SWIR2 & $2.09-2.35$ & 30 & Band 7-SWIR2 & $2.11-2.29$ & 30 \\
\hline & & & & & & & & & Band 8-Pan & $0.52-0.90$ & 15 & Band 8-Pan & $0.50-0.68$ & 15 \\
\hline & & & & & & & & & & & & Band 9-Circus & $1.36-1.38$ & 30 \\
\hline & & & & & & Band 6-TIR & $10.40-12.50$ & 120 & Band 6-1-TIR & $10.40-12.50$ & 60 & Band 10-TIR & $10.60-11.19$ & 100 \\
\hline & & & & & & & & & Band 6-2-TIR & $10.40-12.50$ & 60 & Band 11-TIR & $11.50-12.51$ & 100 \\
\hline
\end{tabular}

${ }^{1}$ The original pixel size for Landsat MSS was $79 \times 57 \mathrm{~m}$; however, most literature reports the spatial resolution of $60 \mathrm{~m}$ because the data has been resampled to $60 \mathrm{~m}$ pixel size. 


\section{Developments of Landsat Data}

The Landsat program has been providing images which have been applied in monitoring the surface of the Earth since 1972 [14]. In January 2015, the Landsat archive held over five million unique images [4]. While other satellites were launched to monitor the Earth's surface in the last three decades, the Landsat program is unique in the application of land cover classification because: (1) it is the longest running uninterrupted Earth observation program; and (2) its archives are the first to offer global images free of charge $[4,16]$.

The long archive period of Landsat images offers researchers a chance to gain insights into past trends which are important when monitoring land cover changes [4,14]. Haack [1] indicated that Landsat images are used to solve problems of having inadequate information on the quality and quantity of resources, especially in developing countries. Furthermore, studies which cover larger areas can be more costly if commercial satellite images are used. However, the free access to Landsat images offers opportunities to researchers who cannot afford commercial satellite images because of the higher prices $[16,23,24]$. This solves the problem of many resource constrained researchers as these images can be accessed free of charge.

Landsat images are constantly improving due to new generations of satellites being launched with new and improved sensors [14,15]. The improvements are mainly defined by the richness in spectral, spatial, radiometric and temporal resolution [18]. Landsat MSS has a spatial resolution of $60 \mathrm{~m}$ while Landsat TM, ETM+ and OLI have a spatial resolutions of $30 \mathrm{~m}$. Additionally, Landsat ETM+ and OLI have a panchromatic band with a spatial resolutions of $15 \mathrm{~m}$ which can be used to improve the spatial resolution of other bands by using a pan-sharpening technique [4]. Landsat MSS images have a radiometric resolution of 6 bits, Landsat TM has eight bits, Landsat ETM+ has nine bits, and Landsat OLI has 12 bits radiometric resolution $[25,26]$. With respect to spectral resolution, Landsat MSS has four bands, Landsat TM has seven bands and ETM+ has eight bands. However, the malfunction of the Scan Line Corrector (SLC) on the ETM+ sensor makes the application of ETM+ images limited $[27,28]$. The latest version of the Landsat images, the Landsat OLI, has 11 bands (Table 1). Current research indicates that Landsat OLI images give good results in many applications as they have good qualities $[18,29,30]$. Choosing the appropriate Landsat images is important; however, researchers will be faced with a few limitations because of the uniqueness of sensors at a particular time, and data gaps in the Landsat archives [4]. The data gaps have greatly reduced because of the on-going Landsat archive consolidation initiative which started in 2010 [4,31].

Landsat data is stored by a network of ground systems located in different countries through a community of international co-operators (IC) and other stations owned by the United States Geological Survey (USGS) [4]. In the past, the ICs had a mandate of receiving and distributing the data to other users at a fee; however, an open access policy was adopted in $2008[14,16]$. Over the years, the ICs around the world collectively accumulated more data than the USGS archives. This means that the Landsat images held by USGS were limited compared with collective images held by ICs around the world. In 2008, the USGS recognized the need for consolidating their Landsat database through a Landsat Global Archive Consolidation (LGAC) initiative and this program, which started in 2010, was initially planned for six years; however, the program is still on-going [4]. The total number of Landsat images held by USGS archives before the consolidation process was reported to be over 5 million in 2015. The consolidation process identified additional 2.5 million images around the world to fill the data gaps. By 2016, more than 2.3 million unique images had been identified and were yet to be added to the USGS archives [4]. The consolidation program aimed at minimizing the data gaps and securing the global dataset by creating a database in a common format. The number of unique images available on the USGS Earth Explorer are a testament to the success of the LGAC program [31]. At the end of 2016, more than $57 \%$ of the images held by USGS were from this initiative; however, the USGS is still not a one-stop-shop and there are no indications if or when this may happen. Nevertheless, the consolidation program is on-going. The USGS still has small data gaps due to the 
challenges in converting the data collected from some of the ICs, because they are in unknown formats or not in good condition [4].

\section{Landsat Land Cover Classification Methods}

\subsection{Early Landsat Land Cover Classification: Visual Approach}

The early Landsat land cover classification methods were similar to those used in conventional aerial photo interpretations in the 1950s and 1960s [13,32]. Generally, Landsat images were used in the same way as aerial photographs, which were rich sources of information for spatially characterizing landscapes on cartographic maps with different scales [10,33]. In the early 1970s, Landsat land cover classification was visual and manual. This was done through the examination of printed aerial images [7,34]. Haack [1] mentioned that the images were in print format and were obtained as black and white composite or individual bands.

Early land cover classification with Landsat images involved delineating land cover classes in a systematic way by marking boundaries of land cover types by using transparent surfaces. In the final stage of classification, the land cover types were marked with specific symbols to differentiate land cover types $[11,35]$. In visual classification, the delineation of land cover was based on the differences in tones, shapes, sizes and patterns $[7,11]$. Land cover extents were calculated based on derived scales of the relationship of image distance and actual distance on the ground [36,37].

\subsection{Landsat Land Cover Classification Using Digital Format}

\subsubsection{Digital Numbers}

The advancement in digital land cover classification is based on the numerical manipulation of digital number (DN) or brightness values (BV) of remote sensing images (Figure 1). Thus digital images are composed of picture elements called pixels located at the intersection of each row and column of an image [11]. The lower the DN values, the lower the radiance being represented in that pixel (Figure 1). The changes in radiance values in the pixels represent the variation of the land cover surfaces. The DN values are presented in pixels of single images; however, Landsat images are presented as multispectral images in which the same scene is recorded simultaneously in several bands of the electromagnetic spectrum [38].

Digital image processing involves the mathematical transformation of digital values to form useful information relating to land cover types. Image processing generally involves three major stages: (1) pre-processing, (2) image enhancement, and (3) classification. Under pre-processing, the $\mathrm{DN}$ values are calibrated to rectify distortion and remove noise by conducting atmospheric and topographic correction $[38,39]$. The $\mathrm{DN}$ values are processed into radiance values which correspond to top of atmosphere reflectance and ground reflectance through different methods as explained in Song, Woodcock, Seto, Lenney and Macomber [39]. After pre-processing, image enhancement is done to improve the quality and visual appearance of the image; however, this step is not so important and can be omitted. Classification involves mathematical grouping of pixel values (pre-processed DN) into themes which correspond to particular land cover types on the Earth's surface [35,38]. 


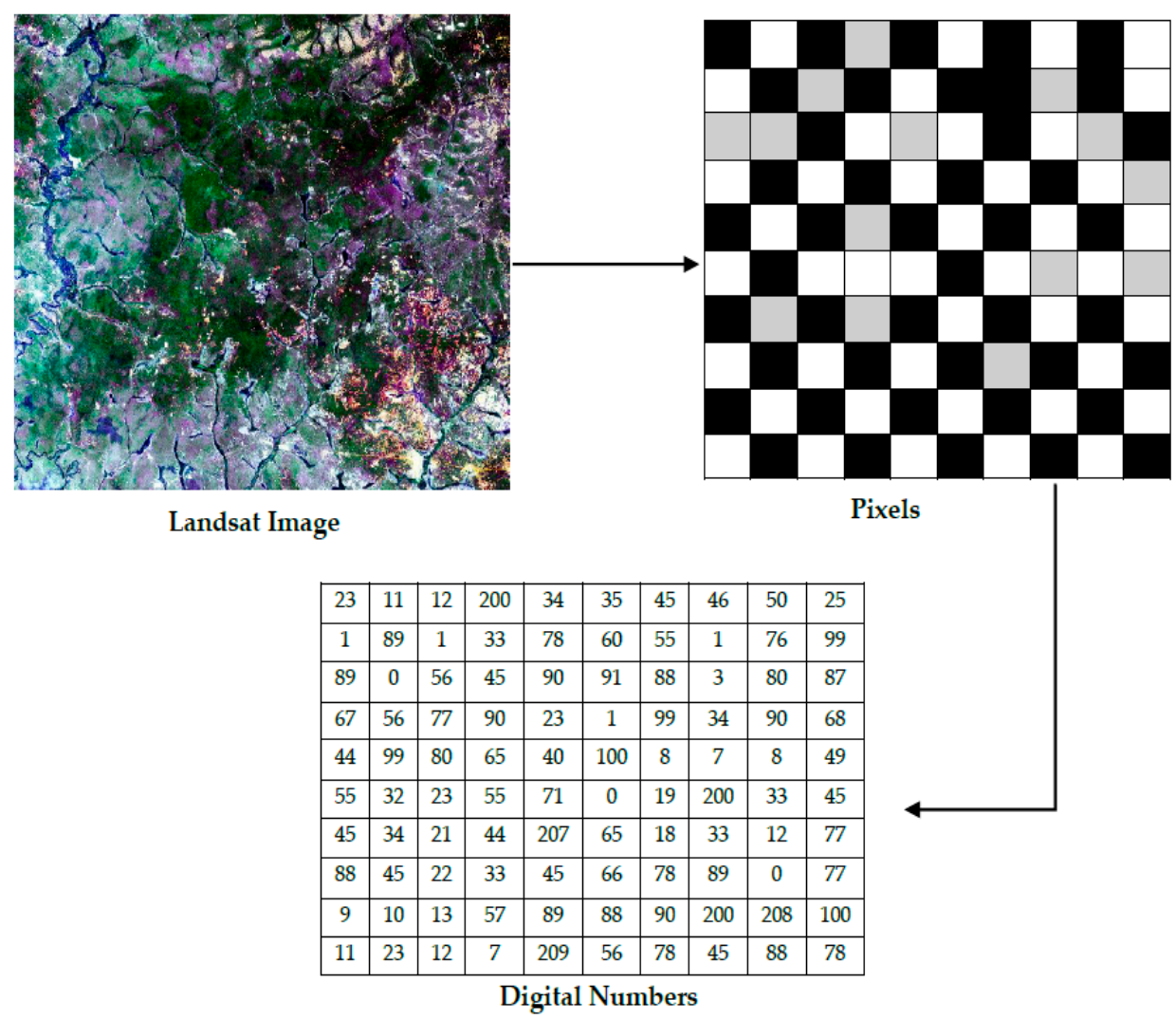

Figure 1. An example of a remote sensing image showing pixels and digital numbers; the arrow shows the progression in the level of detail of information which can be extracted from the images.

\subsubsection{Early Landsat Digital Land Covers Classification Principles}

The Landsat program contributed to the rapid and broad usage of digital analysis of satellite images for Earth's observations because they were the only available satellite images in the early 1970s [5]. In the late 1970s, digital image analysis by computers was carried out only in specialized research institutions; personal computers and many remote sensing software packages which are now available, did not exist $[6,11]$. The development of remote sensing technology advanced in line with the development of GIS which provided the platform for bringing remote sensing data and other geospatial information into a common framework $[5,6]$.

Early automatic methods of image processing can be classified as partial filtering techniques or numerical classification methods [5]. The spatial filtering methods deal with transformation of images into more useful forms and involves processes such as smoothing, sharpening and feature extraction [5]. The numerical classification approach is one of the most important developments in pattern recognition and is the foundation of modern land cover classification methods [11,40]. Generally, pattern recognition employs similarities between objects in classification of land cover types [6]. Modern classification methods were developed from the early pattern recognition techniques and were implemented on computer-automated programs through machine learning and artificial intelligence theories.

The most common types of similarities used in pattern recognition are based on correlation and Euclidean distance between objects [6]. In classification, these techniques may be used as a single technique; however, Steiner [5] reported that a combination of the two techniques produces superior results. Other important aspects of pattern recognition used in classification are discrimination and grouping techniques. Discrimination techniques are useful in establishing boundaries between patterns, which were recognized based on similar properties $[5,6]$. These methods employ linear or non-linear transformation methods depending on the normal distribution of the 
data involved. Steiner [5] reported that non-linear discrimination methods produce results which are more accurate than linear methods. Grouping techniques are more useful in establishing groups of homogeneous characteristics. Generally, the major concern in pattern recognition is to optimize the discrimination and grouping of classes [5].

\subsection{Developments of Computer-Based Land Cover Classification Methods}

Modern methods of land cover classification, called classifiers, developed from numeric approaches to pattern recognition and now run as computer programs [5]. The classifiers are commonly grouped as parametric or non-parametric classifiers. Parametric classifiers are related to probability theories because their classification principles are based on the normal distribution of image values $[9,41]$. Examples of parametric classifiers are maximum likelihood, minimum distance and Bayesian classifiers [42]. The early developments of computer programs for land cover classification were mainly based on a parametric approach as they grouped pixel values based on a probability distribution. On the other hand, non-parametric approaches such as nearest neighbor (NN) are independent of the distribution of the image values and hence are based on deterministic theories [6,11]. The advancement in pattern recognition techniques through artificial intelligence and machine learning approached contributed significantly to the development of advanced non-parametric classifiers such as support vector machine (SVM), artificial neural network (ANN) and decision tree [43].

To date, a number of different classification methods have been developed, especially with the increasing knowledge in the fields of computer science and GIS [6]. The first methods of Landsat land cover classification were developed at pixel level (Figure 2) and hence they are called pixel-based classification [33,41]. The pixel-based approach is commonly divided into supervised and unsupervised classification methods. Classification methods based on sub-pixel level were later developed in the 1980s to address some of the weaknesses of pixel-based classification such as separation of land covers in mixed pixels [44].

In the late 1990s, object based analysis (OBIA) was developed with an approach of classifying images based on grouping pixels rather than operating at an individual pixel $[9,45,46]$. While pixel and sub-pixel based approaches were commonly developed and applied on Landsat images, OBIA classification was developed at a time when finer resolution images were available. Therefore, this method has been commonly applied on finer resolution imagery than Landsat images $[9,19,47]$. 


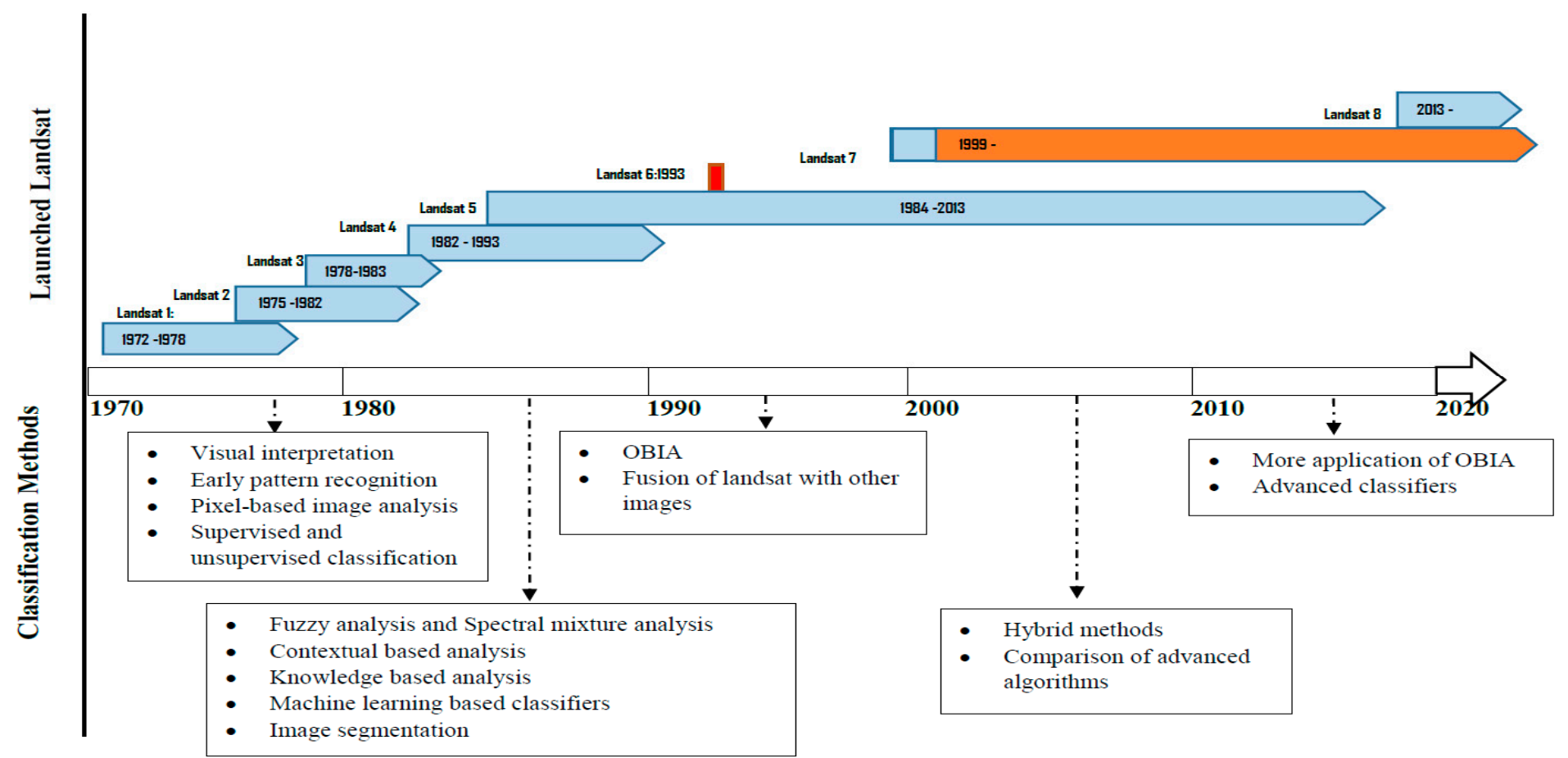

Figure 2. The eight Landsat satellites launched from 1972 to date and corresponding developments of land cover classification methods. The satellite operation periods highlighted in blue indicates operation without interruption, while red indicate failure in launching and orange indicates malfunction. Arrows attached to classification methods are indicative of timing only. 


\subsection{Pixel-Based Classification}

The first methods of automated land cover classification methods were developed in the early 1970s on Landsat MSS and were pixel-based $[7,19,48]$. Pixel-based classification is the process of assigning each pixel to a class by treating each pixel as an individual unit [45]. Pixels within a class are more spectrally similar to one another than they are to pixels in other classes.

\subsubsection{Supervised and Unsupervised Classification}

Pixel-based classification methods are generally grouped as supervised or unsupervised classification. The major difference between supervised and unsupervised classification is that training of the images is involved in supervised classification while no training is done for unsupervised classification $[19,49]$. Data training is the process of selecting a sample of pixels from the image and using it to establish thresholds to delineate specific land covers on the ground. A representative set of pixel values for each class is key for the implementation of a supervised classification. Unsupervised classification methods do not require prior knowledge of land cover types before classification and the interpreter is responsible for assigning a class to each cluster of pixels [6]. Under unsupervised classification, clustering algorithms are used to define and group pixels of similar classes based on spectral values.

Both supervised and unsupervised classification methods were developed in the early 1970s when Landsat MSS images were the only available satellite images (Figure 2). Unsupervised classification was developed first through different clustering methods such as K-means and Interactive Self-Organization Data analysis (ISODATA) [7,50,51]. The most common classifiers under supervised classification are maximum likelihood, minimum distance and artificial neural network (ANN) [19,52,53]. Townshend and Justice [54] highlighted that it is difficult to completely separate supervised and unsupervised classification because of their similarities in the operation. Furthermore, methods called bagging, boosting or hybrid which combine both approaches have been developed to improved pixel-based classification $[9,19,55]$. The last decade has seen the development of these hybrid classification methods in order to compliment the strength of different classification methods [7].

\subsubsection{Parametric and Non-Parametric Classifiers}

Most of the classifiers under pixel-based classification are grouped into two groups: parametric and non-parametric classifiers [5,7]. Parametric classifiers assume that the data is representative and normally distributed. Although parametric classifiers such as maximum likelihood have proved to be useful, these classifiers have two major drawbacks in land cover classification: (1) data of high heterogeneous land covers are usually not normally distributed; and (2) a lot of uncertainty is associated with distribution of land cover surfaces which cannot be described based on data distribution [9].

Non-parametric classifiers such as SVM and ANN have proved to be more useful because they do not base classification on a normality assumption or statistical parameters [56]. Lu and Weng [9] explained that non-parametric classifiers are suitable when using non-spectral data in classification and that these classifiers provide better results than parametric classifiers in complex landscapes.

\subsubsection{Contextual-Based Approach}

The principles of contextual-based classification are based on information which is derived from spatial and spectral relationships among pixels within a given image. Contextual-based classifiers were developed in the 1980s to deal with the problems of interclass spectral variation $[57,58]$. This approach was applied to both classified and unclassified pixels, for example, Magnussen, et al. [59] applied contextual classification to classify forest cover and compared different contextual classifiers with maximum likelihood. Contextual-based approaches usually operate on preliminary classification to reassign pixels to appropriate classes according to contextual information such as the position of the classified pixels in relation to other pixels and spatial data [7]. 
Contextual-based classifiers simulate higher order processes used by human interpreters in order to derive the position of neighboring objects based on the relationship of pixels [57,58]. A common contextual classifier is the Markov random field based classifier. Li, Zang, Zhang, $\mathrm{Li}$ and $\mathrm{Wu} \mathrm{[19]} \mathrm{in} \mathrm{a}$ detailed review of spatial-contextual classification for land cover classification grouped the classifiers into texture extraction, Markov random fields and image segmentation methods. Generally, contextual classification methods are commonly used as a post-classification smoothing technique on already classified images and hence they are important for reclassifying misclassified pixels [7,9].

\subsubsection{Multiple (Hybrid) Classifier Approaches}

It is difficult to choose the best classification method because each classification method has its own strengths and limitations. For example, supervised methods such as maximum likelihood will perform better with sufficient training points and normally distributed image values [9]. However, such methods do not give reliable results in complex landscapes and hence the need for other complimentary methods through hybrid approaches. Early hybrid methods were developed using Landsat images and became common in the 1980s just after the development of supervised and unsupervised classification. However, the development of more advanced classifiers in the last decade has made the hybrid approach more diverse and powerful [60,61]. In most cases, the results from hybrid approaches depend on a number of factors such as quality of pre-processing, experience of an analyst and performance of the classifiers.

Improved classification results may be obtained depending on the combination of different classification methods [9]. Recent studies have shown that the integration of different approaches or classifiers can improve the quality and accuracy of a Landsat land cover classification (Table 2) $[7,19]$. For example, maximum likelihood and ANN were combined to improve land cover classification using Landsat TM; the results had a higher accuracy as compared to using individual methods [62].

\subsection{Sub-Pixel Image Classification}

Sub-pixel based classification was developed because most landscapes are made of different land cover types which might not be easily separated during classification by ordinary pixel-based classification [63-65]. In pixel-based classification, it is assumed that a pixel is made up of one homogenous land cover type; however, many pixels record more than one land cover types $[63,66,67]$. Considering Landsat's ground resolution of between 60 and $30 \mathrm{~m}$, a number of land cover classes can constitute a single pixel. The challenges of multiple land cover types in one pixel are common in Landsat images and can be minimized by using sub-pixel methods [44,68]. Sub-pixel classification approaches were developed in the 1980s based on fuzzy-set theory, Dempster-Shafter theory and certainty factor theory $[7,19,69]$. The most common methods of sub-pixel classification are fuzzy-set techniques and spectral mixture analysis (SMA) $[9,19]$.

\subsubsection{Fuzzy Approach}

In order to improve classification accuracy of tradition classification methods such as maximum likelihood classification, fuzzy classification methods were developed based on a fuzzy-set technique $[44,69,70]$. The early developments and application of sub-pixel methods with Landsat images has been reported in Wang [69], Fisher and Pathirana [44] and Melgani, et al. [71]. In fuzzy-set techniques, each pixel receives a partial membership of all possible classes, thus the extent of each class within each pixel can be estimated [44].

When using this method, each land cover is assigned a fuzzy membership depending on its proportion in each pixel. The proportions are in form of ratios, percentages or probabilities which are converted to actual areas on the ground. Zhang and Foody [70] reported high classification accuracies of up to $93 \%$ when fuzzy classification method was used as compared to maximum likelihood pixel-based method with $61 \%$. Fuzzy classification has proved important for solving mixed 
pixels problems; however, it has not been commonly applied in practical terms because it is not easy to use compared to other classification methods [68,72].

\subsubsection{Spectral Mixture Analysis (SMA)}

SMA has been recognized as the most effective method for dealing with sub-pixel methods, especially for medium resolution imagery like Landsat [66,73]. This method was developed in the early 1980s (Figure 2) and has been applied extensively on Landsat land cover classification $[63,66,67]$. The output of SMA is represented as a fraction of each land cover type called endmembers [74]. For example, Mayes, Mustard and Melillo [23] applied SMA in establishing the extent of dry tropical forests in Tanzania by establishing the fraction of forest and non-forest endmembers. Most studies have indicated that SMA is important in improving area estimation of land cover types $[23,75,76]$.

SMA and sub-pixel based classification in general are important for effective classification of Landsat images as they are of medium resolution and are usually used for large areas which have heterogeneous land cover types and are likely to have mixed pixels $[9,66,75]$. The common forms of SMA are linear spectral mixture analysis (LSMA) and multiple endmember spectral mixture analysis (MESMA). LSMA is designed to work with a fixed number of endmembers while MESMA can be used on pixels with different numbers of endmembers $[23,77]$. The major challenge for SMA is the errors in the final allocation of fractional endmembers resulting from spectral variability and similarity during the selection of endmembers $[66,67]$.

\subsection{Object-Based Approach}

Object-based image analysis (OBIA) uses geographic objects as basic units for land cover classification $[78,79]$. This approach reduces the within class variation and generally removes salt-and-pepper effects which result from isolated pixels mainly due to misclassification. OBIA has an advantage because it incorporates various sources of information like texture, shape and position as the basis for classification $[19,48,80]$. The initial developments of remote sensing object-based classification approaches were done on Landsat MSS images in the 1970s (Figure 2) by Kettig and Landgrebe [81]. The application was known as Extraction and Classification of Homogeneous Object (ECHO). Object-based theories and concepts improved in the 1990s and were commonly applied as a segmentation procedure; however, the application of these concepts faced the challenge of not having a user-friendly interface [7,82]. A German company called Definiens developed Cognition Network Technology (CNT) through Nobel laureate Professor Gerd Binnig and team, which was later launched as eCognition in May 2000 [7,83]. The eCognition software provides a systematic approach and user-friendly interface that permits implementation of concepts developed in the past [7,48,82]. In June 2010, Definiens sold its earth science market assets, including eCognition software and the patent license for CNT to Trimble Navigation Ltd [83].

Object-based methods are commonly applied to images with high spatial resolution such as IKONOS, GeoEye, QuickBird and SPOT; however, this method has also been applied in land cover classification using medium resolution Landsat images [19,84,85]. For example, object-based classification was used on Landsat MSS, TM and ETM+ for land cover classification in Ethiopia and on urban sprawl in Eritrea [86,87]. Dorren, Maier and Seijmonsbergen [78] applied OBIA on Landsat TM images to classify vegetation on rugged terrain in Montafon region of Austria. OBIA has also been applied on Landsat MSS, TM, ETM+ to classify land cover by using new machine learning techniques such as Random Forests, Nearest Neighbours and SVM [88,89]. The new Landsat images, Landsat OLI, produced good results (overall accuracy above 90\%) when used with OBIA to map different land cover types such as urban areas [29] and agricultural areas [90]. While object-based land cover classification has been effective on different Landsat images, not much has been reported on the performance of OBIA on the earlier version of Landsat images (Landsat MSS) perhaps because of their lower spatial resolution, or the availability of newer imagery [91,92]. 
The success of eCognition (Trimble Navigation Ltd, Sunnyvale, CA, USA) [82] triggered the development of other commercial OBIA software such as Feature Analyst (Textron Systems, Providence, RI, USA), ENVI Feature Extraction (HARRIS ${ }^{\circledR}$, Melbourne, FL, USA) and ERDAS Imagine (Hexagon Geospatial, Madison, AL, USA). Open source software such as SAGA (SAGA User Group) [93] and GRASS (GRASS Development Team) are also available for OBIA land cover classification [94]. OBIA software differs mainly in the way segmentation is done and also the cost. Setting cost aside, eCognition and ENVI Feature Extraction segments the whole image while Feature Analyst extracts target features without segmenting the entire image. Feature Analyst is implemented as an extension in ArcGIS and ERDAS imagine, as such, it is important to have host software [95].

Research comparing OBIA software is rare, with most researchers preferring to focus on algorithm development and classification performance of individual software packages [96,97]. Most studies that have focused on comparison have applied the software to high-resolution imagery. For example, Tsai, et al. [98] compared Feature Analyst, which is based on spatial contextual machine learning classification, with Feature Extraction in ENVI for their ability to delineate buildings in QuickBird imagery. Using a measure called correctness, Feature Analyst performed better (62\%) than ENVI Feature Extraction (56\%), though the authors did not speculate about the reasons for this result. Meinel and Neubert [99] compared seven software packages for segmenting IKONOS imagery. Based on different standards such as quality of segmentation without considering classification accuracy, they found that eCognition segmentation was better than the alternatives, including ERDAS Imagine, for a variety of reasons including having different segmentation algorithms and classifiers [82,99]. Software comparison studies using medium resolution imagery are more rare, though Landsat ETM+ imagery was used in a study comparing the performance of SAGA with eCognition [93]. In this study, the open license SAGA segmentation algorithm was robust in comparison with the commercial eCognition software algorithm.

\subsubsection{Comparisons of OBIA and Pixel-Based Classification Methods of Landsat Images}

A number of studies were conducted to compare the performance of object-based and pixel-based classification of Landsat imagery. In most of these studies, OBIA produced higher classification accuracies across various land cover types [82,90,100,101]. For example, Flanders, Hall-Beyer and Pereverzoff [82] used Landsat ETM+ to evaluate the performance of eCognition by comparing the accuracy of OBIA with pixel-based classification on different forest types. OBIA resulted in a $90 \%$ classification accuracy, while the pixel-based approach yielded a $66 \%$ accuracy. Similar results were attained by Frohn, et al. [102], whereby OBIA had an accuracy of $90.8 \%$ and a pixel-based classification had an accuracy of 78\% when Landsat ETM+ was used to classify wetlands in Florida. Li, Wang, Wang, $\mathrm{Hu}$ and Gong [89] reported that OBIA classified Landsat TM imagery of a heterogeneous landscape with $92 \%$ accuracy, exceeding the $84 \%$ accuracy achieved with a pixel-based approach. Zerrouki and Bouchaffra [103] also reported that OBIA had a high classification accuracy of $92.7 \%$ compared to $78 \%$ accuracy for a pixel-based classification of Landsat ETM+ imagery. It should be noted that while the overall accuracy of OBIA classification tends to exceed the overall accuracy of pixel-based approaches, the classification accuracy of some individual land cover classes could be higher for a pixel-based approach $[46,83,102,104]$.

Not all studies have reported higher classification accuracy for object-based over pixel-based classification of Landsat imagery. For example, Dingle Robertson and King [101] reported that the accuracy for both OBIA and pixel-based approaches was 70\% on Landsat ETM+. This was attributed to the absorption of small classes by large classes during segmentation in OBIA. Similar results were attained by Dorren, Maier and Seijmonsbergen [78] when OBIA was compared with pixel-based classification on forest located in the steep Austrian mountains. Notwithstanding the previous example, OBIA tends to result in greater accuracy than pixel-based classification approaches. It's believed that the superior classification accuracy is due to OBIA's segmentation algorithms, and also the ability to use spectral, textural, and neighborhood information during classification [82,88,92,104]. In support of 
this latter point, Cai and Liu [100] showed that the results of pixel-based classification of Landsat TM were improved from 82 to $87 \%$ and they matched the accuracy of OBIA when pixel-based classification was enhanced with contextual information.

\subsubsection{Limitations of OBIA Land Cover Classification of Landsat Images}

The superior performance and strengths of OBIA are well documented for fine spatial resolution images compared to the limitations, especially for Landsat images $[94,105,106]$. The major limitation of OBIA on Landsat land cover classification are: (1) low resolution of Landsat images, (2) segmentation scale, and (3) the workflow associated with OBIA. The extraction of small land cover types requires high levels of spatial detail, which are limited in Landsat images, considering the 60 and $30 \mathrm{~m}$ spatial resolutions. Darwish, et al. [107] compared the classification accuracy of Landsat TM with Resourcesat-1 (IRS) images which have a $20 \mathrm{~m}$ spatial resolution. The results showed that the accuracy of small land cover types such as building, orchards and small water bodies was low for Landsat images, mainly because of the low spatial resolution. Similar results were obtained in Ethiopia when OBIA was used in land cover classification with Landsat MSS (60 m resolution), Landsat ETM+ (30 $\mathrm{m}$ resolution) and RapidEye images (5 $\mathrm{m}$ resolution) in which the accuracy increased from $85.7 \%$ for Landsat MSS to $90.7 \%$ and $93.2 \%$ for Landsat ETM+ and RapidEye respectively [86].

OBIA land cover classification using Landsat images also faces a challenge of selecting the optimal segmentation scale $[108,109]$. When the segmentation scale is not appropriate, the image can be under or over segmented [102]. Under segmentation means that the image-objects are larger than the objects on the ground while over segmentation results in more subdivision. Under segmentation affects classification accuracy by increasing the chances that two or more land covers will be included in one large image object, thus resulting in errors of commission. Dronova, Gong, Clinton, Wang, Fu, Qi and Liu [109] tested segmentation scales ranging from 1 to 10 when classifying wetland areas using Landsat TM and reported that the highest classification accuracy occurred at a segmentation scale of 8 , which created coarse objects. Likewise, over segmenting an image can result in a real world object being split into two or more objects of differing classes, especially with low spatial resolution images such as Landsat images $[78,102]$.

Although different formal approaches, such as using an estimation of scale parameter (ESP) tool [110] and a segmentation index [108], were developed to address the challenges of establishing the optimal segmentation scale, using trial-and-error remains the most common approach of selecting the optimal segmentation scale. Hence, segmentation scale remains an important issue in Landsat land cover classification when using OBIA [102,108]. The general practice for selecting an appropriate segmentation scale for Landsat images is to visually compare the segmentation quality for a range of segmentation scale values [108]. The appropriate segmentation scale occurs at a point when the segmented objects are large and match target objects on the ground; thus this approach is subjective $[78,108]$. Kindu, Schneider, Teketay and Knoke [86] reported that the scale parameter increases with an increase in spatial resolution; for example, the scale parameter used was 5 for Landsat MSS, 8 for Landsat ETM+ and 50 for RapidEye. Based on available studies on Landsat classification with OBIA, the range for the segmentation scale for Landsat MSS is 5-10, Landsat TM, ETM+ and OLI the range is 5-20, and for pan-sharpened ETM+ and OLI it is 20-50 [78,87,90,102,108]. For all these images, the other segmentation parameters, shape and compaction, were reported to be $0.1-0.5$ and $0.5-0.8$ respectively $[86,87]$.

The variation in classification accuracy when a range of segmentation scales is used in Landsat land cover classification has also been tested in some studies. Dronova, Gong, Clinton, Wang, Fu, Qi and Liu [109] used Landsat TM on wetlands and showed that the classification accuracy increased from $75 \%$ with a segmentation scale of 2 , to the highest accuracy of $90 \%$ at a scale of 8 , and then decreased to an accuracy of $80 \%$ at a scale of 10 . Similar results were reported in Dorren, Maier and Seijmonsbergen [78] in which the classification accuracy was low $(62 \%)$ at a segmentation scale value of 2 , increased to its highest value (73\%) at a scale of 20 , before decreasing to $40 \%$ at a large scale factor 
of 80. This pattern was consistent in most of the studies where different segmentation scales were tested on different land cover types such as cropland [90], wetland areas [102] and other land cover types such as forests, water bodies and urban areas [108].

Another potential drawback of OBIA, which also applies to Landsat images, is related to workflows, which involve many steps and can be a source of variation, uncertainty and error [82]. These steps, such as selecting segmentation scale, choosing a segmentation method, sample selection, training, developing rule sets and choosing classifiers when using automated classifiers can make comparing results between studies difficult $[88,92,109]$. Nevertheless, in the last decade, OBIA has become common compared to pixel and sub-pixel based classification methods as indicated by the continuous increase of published studies on OBIA (Figure 3).

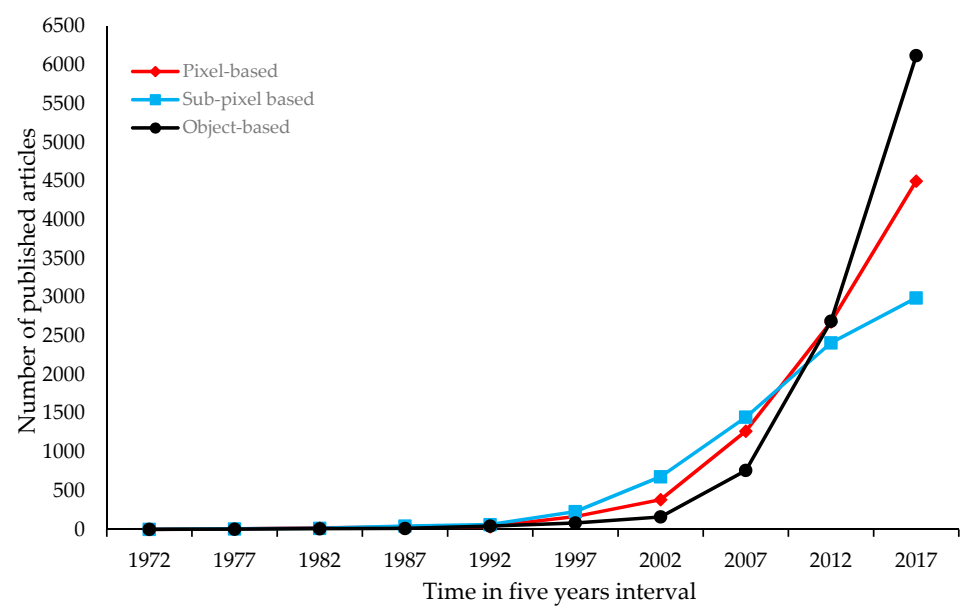

Figure 3. The number of published articles on pixel, sub-pixel and object-based Landsat land cover classification methods from Google Scholar.

\subsubsection{Knowledge-Based Approaches}

Knowledge-based land cover classification uses existing auxiliary data as a means of developing rules for classification. Tailor, et al. [111] reported the development and application of knowledge-based imaged land cover classification with Landsat MSS in the early 1980s (Figure 2). The advancement in the development of knowledge-based image classification can be attributed to the availability of geospatial information and the development of GIS which is used for combined analysis of different spatial information [9]. Common auxiliary data used include digital elevation models (DEM), existing maps, population densities and climatic data [112].

Knowledge-based methods relate land cover types to auxiliary data, for example, vegetation can be related to slope, elevation or aspect. The procedure for this method involves developing rule sets which have binding thresholds in relation to particular land cover types $[9,111,113]$. The development of knowledge-based image classification is closely associated with image segmentation as the clusters depend on rule sets developed from other datasets apart from spectral information $[9,111]$. Different knowledge-based classifiers were developed such as decision trees which use thresholds from auxiliary data to delineate land cover types [9].

\section{Landsat Image Fusions in Land Cover Classification}

One major advancement in the application of Landsat images in land cover classification is the integration of other images with Landsat images through image fusion techniques [114]. The development of effective fusion algorithms coupled with the advent of new remote sensing data such as advanced very high-resolution radiometer (AVHRR) and moderate-resolution imaging spectroradiometer (MODIS) has made Landsat images more useful in land cover classification [114,115]. For example, Landsat and MODIS was used to develop improved images for land cover classification 
in China and Southwest Missouri, Unites States of America (USA) [27,85]. AVHRR and MODIS have low spatial resolution ranging from 0.25 to $8 \mathrm{~km}[17,85,116]$; however, these images have an advantage of having a high temporal resolution of one day $[115,117]$. On the other hand, Landsat images have a higher spatial resolution as compared to MODIS and AVHRR. However, the temporal resolutions of 18 or 16 days for Landsat images are not ideal for monitoring rapid land cover changes such as fire incidences. Therefore, complementing Landsat with MODIS or AVHRR, which has a high temporal resolution of one day, has the potential to take advantage of the best qualities of each type of imagery [27,118].

During the past two decades, Landsat images have also been integrated with different data such as panchromatic images, radio detection and ranging (Radar), light detection and ranging (LiDAR) and high-resolution images [114]. The spatial resolution of Landsat ETM+ and OLI images can be improved from 30 to $15 \mathrm{~m}$ using panchromatic sharpening (pan-sharpening) and this technique has been shown to improve classification accuracy [90]. Landsat ETM+ images were integrated with synthetic aperture radar (SAR) in monitoring protected areas in Uganda [117]. Fusion of multispectral images such as Landsat ETM+ and SAR has two major advantages: (1) enhancement of spectral information; and (2) reducing the problem of cloud cover because SAR is less affected by cloud cover [119]. LiDAR was also integrated with Landsat ETM+ images in order to improve mapping of vertical and longitudinal characteristics of different land cover types [120-122]. Generally, when correct algorithms are applied during image fusion of Landsat images with other remote sensing data, improvements are expected on the results of land cover classification $[117,123,124]$.

\section{Comparative Performance of Different Landsat Images in Land Cover Classification}

Over the last for four decades, four types of Landsat images, Land MSS, TM, ETM+ and OLI, have been used in different land cover classification applications. A number of studies reported different results on the comparison of these images in land cover classification. For example, Toll [125] compared the performance of Landsat MSS to Landsat TM images in land cover classification and reported that Landsat TM images are superior to Landsat MSS images. The major reason for the superior performance of Landsat TM images was attributed to the higher spatial resolution, addition of more spectral bands and the increase of radiometric resolution from 6 bit for Landsat MSS images to 8 bit for Landsat TM images [4,125]. In a separate study on the performance of Landsat MSS and TM by Haack, et al. [126]; it was reported that Landsat TM images were more useful in separating more homogenous near-urban land cover types as compared to heterogeneous urban areas. Most research has indicated superior performance of Landsat TM as compared to Landsat MSS [125,126] with a difference in accuracy of between 5 and 7\% [127].

Landsat ETM+ as a sensor has improvements as compared to the previous version of Landsat images (Landsat MSS and TM) because of the higher geodetic accuracy, high radiometric resolution (9 bits) and reduced periodic sensor noise [2]. In addition, the introduction of a $15 \mathrm{~m}$ resolution panchromatic band was a major improvement to the ETM+, especially in the application of land cover classification [4]. The comparisons of ETM+ with MSS and TM in land cover classification indicate that the performance of ETM+ is superior to the earlier versions of Landsat images [18]. Masek, Honzak, Goward, Liu and Pak [2] reported that the superior performance of ETM+ in land cover classification indicates a major improvement of the sensor based on higher geodetic accuracy and reduced noise levels [18,29].

The launch of Landsat OLI, which produces Landsat OLI images, has proved to be a good alternative to the malfunctioning ETM+ line scanner. Recent studies indicated that Landsat OLI performed better than Landsat TM and ETM+ images [18,29]. The performances of Landsat ETM+ and OLI were compared to Landsat TM by using different classification methods such as OBIA, SVM and maximum likelihood methods; the results indicated that the performance of all the images largely depended on the methods of classification $[29,128]$. Here, OBIA performed better with Landsat OLI while the use of SVM was good for all the images (Table 2). The differences in the classification results of Landsat OLI and ETM+ are associated with the narrow spectral band of Landsat OLI [18]. 
Table 2. Summary of land cover classification overall accuracies with different classifiers applied on specific Landsat images and land cover type.

\begin{tabular}{|c|c|c|c|c|c|c|}
\hline Classification Approach & Method & Classifier Used & Landsat Images Used & Type of Land Cover & Accuracy Attained (\%) & Source \\
\hline \multirow{17}{*}{ Pixel-based } & \multirow{4}{*}{ Supervised } & $\mathrm{ML}, \mathrm{NN}, \mathrm{SVM}$ & MSS, TM, OLI & Urban area & $73-82$ & {$[29,125,129]$} \\
\hline & & ML & MSS, TM, OLI & Forest plantation & $61-90$ & [129-131] \\
\hline & & ML & MSS, OLI & Dense forest & $68-90$ & [129-131] \\
\hline & & ML & TM, OLI & Open forest & $52-81$ & {$[129,132]$} \\
\hline & \multirow{4}{*}{ Unsupervised } & ISODAT & TM & Urban area & $78-94$ & {$[55,133]$} \\
\hline & & ISODAT & $\mathrm{TM}$ & Forest plantation & $71-87$ & {$[133-135]$} \\
\hline & & ISODAT & TM, OLI & Dense forest & $71-87$ & [133-135] \\
\hline & & ISODAT & TM & Open forest & $69-81$ & {$[133,135]$} \\
\hline & \multirow{5}{*}{ Contextual } & ECHO, Majority filter & TM & Urban area & $72-81$ & {$[136,137]$} \\
\hline & & ECHO, Majority filter & $\mathrm{TM}$ & Forest plantation & $70-81$ & {$[136,137]$} \\
\hline & & ECHO, Majority filter & TM, ETM+ & Dense forest & $72-82$ & {$[136,137]$} \\
\hline & & NN & MSS & Open forest & $66-90$ & {$[57,136,137]$} \\
\hline & & ECHO, Majority filter & TM, ETM+ & Agricultural area & $66-97$ & {$[136,137]$} \\
\hline & \multirow{4}{*}{ Hybrid } & ISODAT, fuzzy, ML & TM, ETM+ & Urban area & $64-96$ & {$[138,139]$} \\
\hline & & ML, Rule based, ISODAT & TM, ETM+, DEM & Forest plantation & $74-87$ & {$[138,139]$} \\
\hline & & ML, Rule based, ISODAT & TM, ETM+, DEM & Dense forest & 79-91 & {$[138,139]$} \\
\hline & & ML, Rule based, ISODAT & TM, ETM+ & Agricultural area & $64-84$ & {$[138,139]$} \\
\hline \multirow{10}{*}{ Sub-pixel } & \multirow{5}{*}{ SMA } & LSMA, MESMA & TM, ETM+, OLI & Urban area & $83-90$ & {$[29,77]$} \\
\hline & & LSMA & $\mathrm{TM}$ & Forest plantation & $77-93$ & {$[73,76]$} \\
\hline & & LSMA & TM, OLI & Dense forest & $75-93$ & {$[23,73]$} \\
\hline & & LSMA & TM & Open forest & $77-87$ & {$[73,140]$} \\
\hline & & LSMA & TM, OLI & Agriculture area & $70-74$ & {$[23,141]$} \\
\hline & \multirow{5}{*}{ Fuzzy analysis } & Fuzzy C-Mean & MSS & Urban area & $70-90$ & {$[44,71]$} \\
\hline & & Fuzzy partitioning & $\mathrm{TM}$ & Forest plantation & $74-90$ & {$[68,69]$} \\
\hline & & Fuzzy membership & TM & Dense forest & $74-70$ & {$[44,64]$} \\
\hline & & Explicit fuzzy & TM & Open forest & $56-79$ & {$[44,71]$} \\
\hline & & Explicit fuzzy & TM & Agriculture & 74-92 & {$[68,71]$} \\
\hline \multirow{8}{*}{ Object-based } & \multirow{4}{*}{ OBIA $^{1}$} & SVM, DT, RF, NN & ETM+, TM, MSS, OLI & Urban areas & $73-98$ & {$[29,84]$} \\
\hline & & Decision rule & ETM+, TM & Forest plantation & $80-97$ & {$[45,84,101]$} \\
\hline & & Decision rule & TM & Natural forest & $77-95$ & {$[45,78,84,101]$} \\
\hline & & Decision rule & $\mathrm{TM}$ & Agriculture area & $76-90$ & {$[78,101]$} \\
\hline & \multirow{4}{*}{ Knowledge based } & Expert-knowledge & MSS, TM & Urban area & $87-90$ & {$[111,113,142]$} \\
\hline & & Spectral expert & MSS, TM, DEM & Forest plantation & $86-94$ & {$[142,143]$} \\
\hline & & Spectral expert & MSS, TM, DEM & Dense forest & $85-92$ & {$[142,143]$} \\
\hline & & Eco-SDSS & MSS, TM, GIS & Agriculture area & $85-88$ & {$[112,142]$} \\
\hline
\end{tabular}

Note that the values of accuracies presented range from the lowest to the highest overall accuracies for each land cover type. ML is maximum likelihood, NN is nearest neighbor, LSMA is linear spectral mixture analysis, MESMA is multiple endmember spectral mixture analysis and RF is random forests. ${ }^{1}$ The scale parameter range between $5-10$ for Landsat MSS and 5-20 for Landsat TM, ETM+ and OLI while shape and compaction were reported to be $0.1-0.5$ and $0.5-0.8$ respectively. 


\section{Best Practices for Landsat Land Cover Classification}

In order to obtain the best classification results from Landsat images, a number of factors such as the selection of an ideal classification method and classifier, the quality of pre-processing and the type of Landsat images being used need to be considered $[18,39,144]$. It is important to employ geometric and radiometric correction on the images using appropriate methods [39]. A lot of variation can be attained depending on the quality of the pre-processing calibration done on the images before classification, especially in areas with topographic variations $[145,146]$.

Geometric correction includes orthorectification and registration of the images with ground points. Orthorectification involves correcting the errors resulting from tilting of the platform on which the sensor is mounted in order to produce a planimetrically correct image. This tilting usually results in distortion in the scale parameters of the images $[145,147]$. Although geometric corrections are important to Landsat land cover classification, most studies do not apply these corrections because National Aeronautics and Space Administration (NASA) provides images which are already geometrically corrected and orthorectified to a level called Landsat Level 1 (L1T) [147,148]. However, Tatem, Nayar and Hay [147] reported that in a few circumstances, Landsat images did not produce the desired results because they were not geometrically correct; therefore, it is important to check the geometric accuracy of the Landsat images before further processing.

The major sources of geometric errors are insufficient ground control points for some scenes, errors in the geo-registration procedures and the level of calibration of a particular Landsat satellite sensor [149]. Most of the scenes have been corrected with sufficient ground control points; however, errors were identified on Landsat 4 and 5 for some scenes such as those from Brazil and Ecuador [150]. The geometric accuracy of L1T products has been increasing with the introduction of new Landsat satellites. For example, Landsat 8 has the highest geometric accuracy of less than $12 \mathrm{~m}$, Landsat TM and ETM+ have accuracy of less than $50 \mathrm{~m}$, while Landsat MSS has a geometric accuracy exceeding $50 \mathrm{~m}$. Roy, et al. [151] highlighted that the Landsat 8 L1T products have high geometric accuracy because of the pushbroom design and the on-board global positioning system (GPS) which aids in geometric correction, unlike the other Landsat satellites which are/were dependent on ground control. For the purpose of land cover and time series studies, the acceptable geometric errors should be less than $12 \mathrm{~m}$ or less than half a pixel and this can be achieved by further georeferencing through image-to-image registration with geometrically accurate images or by using additional ground control points $[149,150]$.

Another important pre-processing step on Landsat images is the radiometric correction, which involves the transformation of $\mathrm{DN}$ values into top of atmosphere and ground reflectance values [39]. The radiometric correction has two major components: (1) atmospheric correction, which deals with effects due to scattering and absorption of electromagnetic waves in the atmosphere; and (2) topographic correction, which comes because of variations on the Earth's surface [145,152,153]. Tatem, Nayar and Hay [147] indicated that it is important to apply atmospheric correction when working with more than one scene in which training datasets are transferred to other scenes. Topographic effects are corrected by adjusting the surface reflectance by using digital elevation models (DEM) [154]. A number of radiative transfer codes, both simple and complex, have been developed for atmospheric correction and common application software for atmospheric corrections include Dark Object Subtraction (DOS) and FLAASH in ENVI and ATCOR which is implemented as a stand-alone software or incorporated in other software such PCI Geomatica [147].

In land cover classification, OBIA, which has become common in the last decade, has proven to be superior to other methods of classification $[101,139,155]$. OBIA produced high classification accuracies in most studies which were based on Landsat images for different land cover types; however, OBIA`has limitations such as choosing the appropriate segmentation scale and dealing with different steps, which can be a source of variation if not properly handled [94]. The ability to use a diverse range of information such as shape, texture and compaction to compliment spectral values makes classification results from OBIA more accurate. Although OBIA has not been commonly applied on the first Landsat images, Landsat MSS, it has proved to perform better on Landsat TM, ETM+ and OLI $[79,88]$. 
SMA has proven to be very useful in complex environments such as the tropics, where the landscape is complex and mixed pixels are common (Table 2). It is worth noting that other classification methods can equally produce high classification accuracies when appropriate procedures are followed (Table 2).

\section{Conclusions}

This review focused on the developments of Landsat land cover classification methods and determining the best ways of using Landsat images in land cover classification. Landsat land cover classification has continued to be an important application, especially with the continuous introduction of new sensors and the change in the data access policy from a commercial to a free access approach $[4,151]$. The new Landsat imagery has improved qualities such as high spectral, spatial and temporal resolution. The fact that Landsat images can be accessed for free for nearly any location on Earth is an added advantage. The land cover classification methods commonly applied to Landsat imagery can be broadly grouped into pixel-based, subpixel-based and object-based approaches. While methods for land cover classification have advanced over the last four decades, the maximum likelihood pixel-based classification method, which was developed in the 1970s, is the most commonly used method on Landsat images [9,29]. Pixel-based classification has limitations such as salt-and-pepper effects and challenges due to mixed-pixels, a common issue in medium resolution imagery like Landsat. The subpixel approach was developed to address the limitations of the pixel-based approach, especially the mixed pixel effects. However, effects due to spectral variability and challenges in selecting representative samples for endmembers still remain major challenges for the subpixel approach [66].

Most studies on Landsat land cover classification have reported the superior performance of OBIA in various landscapes such as urban areas [89,156], agricultural areas $[79,85]$, forests $[86,128]$ and wetlands $[47,157]$. The major advantage of OBIA is that it represents the classification units as real world objects on the ground and hence reduces the within class variability. Although OBIA has been commonly applied on fine spatial resolution images, most studies have indicated its superior performance on Landsat images because it combines different types of information in the classification procedure [89,128]. However, OBIA land cover classification has limitations such as challenges in selecting the optimal segmentation scale, which can generate errors due to over or under segmentation, and misclassification of small land cover types due to the low or medium spatial resolution of Landsat images [94,105]. The OBIA approach also involves many steps in its workflow such as selecting training samples, developing rule sets and choosing classifiers, all of which have the potential to affect the classification accuracy if not properly done [48].

The reviewed studies do not clearly indicate the best classification method for Landsat images, thus it is important to consider the strengths and limitations of each method as compared to other methods and hence most of the classification methods remain useful and have the potential to produce high levels of accuracy. The use of hybrid methods needs to be investigated further because the combination of different classifiers is complex, but from the limited literature, they appear to show promise for land cover classification using Landsat imagery.

Acknowledgments: We would like to thank the anonymous reviewers for their valuable comments.

Author Contributions: D.P. and J.M. contributed to conceptualizing the research. D.P. undertook the literature review. D.P. led the writing, with J.M. contributing some sections.

Conflicts of Interest: As authors, we declare that there is no potential conflict of interest.

\section{References}

1. Haack, B.N. Landsat: A tool for development. World Dev. 1982, 10, 899-909. [CrossRef]

2. Masek, J.G.; Honzak, M.; Goward, S.N.; Liu, P.; Pak, E. Landsat-7 ETM+ as an observatory for land cover: Initial radiometric and geometric comparisons with Landsat-5 Thematic Mapper. Remote Sens. Environ. 2001, 78, 118-130. [CrossRef] 
3. Masek, J.G.; Hayes, D.J.; Joseph Hughes, M.; Healey, S.P.; Turner, D.P. The role of remote sensing in process-scaling studies of managed forest ecosystems. For. Ecol. Manag. 2015, 355, 109-123. [CrossRef]

4. Wulder, M.A.; White, J.C.; Loveland, T.R.; Woodcock, C.E.; Belward, A.S.; Cohen, W.B.; Fosnight, E.A.; Shaw, J.; Masek, J.G.; Roy, D.P. The global Landsat archive: Status, consolidation, and direction. Remote Sens. Environ. 2016, 185, 271-283. [CrossRef]

5. Steiner, D. Automation in photo interpretation. Geoforum 1970, 1, 75-88. [CrossRef]

6. Thompson, M.M.; Mikhail, E.M. Automation in photogrammetry: Recent developments and applications (1972-1976). Photogrammetria 1976, 32, 111-145. [CrossRef]

7. Campbell, J.B.; Wynne, R.H. Introduction to Remote Sensing; Guilford Press: New York, NY, USA, 2011; Volume 5.

8. Ahmad, W.; Jupp, L.B.; Nunez, M. Land cover mapping in a rugged terrain area using Landsat MSS data. Int. J. Remote Sens. 1992, 13, 673-683. [CrossRef]

9. Lu, D.; Weng, Q. A survey of image classification methods and techniques for improving classification performance. Int. J. Remote Sens. 2007, 28, 823-870. [CrossRef]

10. Colwell, R.N. The photo interpretation picture in 1960. Photogrammetria 1959, 16, 292-314. [CrossRef]

11. Reinhold, A.; Wolff, G. Methods of representing the results of photo interpretation. Photogrammetria 1970, 25, 201-207. [CrossRef]

12. Gordon, S.I. Utilizing Landsat imagery to monitor land-use change: A case study in Ohio. Remote Sens. Environ. 1980, 9, 189-196. [CrossRef]

13. Lo, C.P. Landsat images as a tool in regional analysis: The example of Chu Chiang (Pearl River) delta in South China. Geoforum 1977, 8, 79-87. [CrossRef]

14. Turner, W.; Rondinini, C.; Pettorelli, N.; Mora, B.; Leidner, A.K.; Szantoi, Z.; Buchanan, G.; Dech, S.; Dwyer, J.; Herold, M.; et al. Free and open-access satellite data are key to biodiversity conservation. Biol. Conserv. 2015, 182, 173-176. [CrossRef]

15. Hansen, T. A review of large area monitoring of land cover change using Landsat data. Remote Sens. Environ. 2012, 122, 66-74. [CrossRef]

16. Woodcock, C.E.; Allen, R.; Anderson, M.; Belward, A.; Bindschadler, R.; Cohen, W.; Gao, F.; Goward, S.N.; Helder, D.; Helmer, E.; et al. Free access to Landsat imagery. Science 2008, 320, 1011. [CrossRef] [PubMed]

17. Cihlar, J. Land cover mapping of large areas from satellites: Status and research priorities. Int. J. Remote Sens. 2000, 21, 1093-1114. [CrossRef]

18. Zhu, Z.; Fu, Y.; Woodcock, C.E.; Olofsson, P.; Vogelmann, J.E.; Holden, C.; Wang, M.; Dai, S.; Yu, Y. Including land cover change in analysis of greenness trends using all available Landsat 5, 7, and 8 images: A case study from Guangzhou, China (2000-2014). Remote Sens. Environ. 2016, 185, 243-257. [CrossRef]

19. Li, M.; Zang, S.Y.; Zhang, B.; Li, S.S.; Wu, C.S. A review of remote sensing image classification techniques: The role of spatio-contextual information. Eur. J. Remote Sens. 2014, 47, 389-411. [CrossRef]

20. De Sy, V.; Herold, M.; Achard, F.; Asner, G.P.; Held, A.; Kellndorfer, J.; Verbesselt, J. Synergies of multiple remote sensing data sources for REDD+ monitoring. Curr. Opin. Environ. Sustain. 2012, 4, 696-706. [CrossRef]

21. Barbosa, J.; Broadbent, E.; Bitencourt, M. Remote sensing of aboveground biomass in tropical secondary forests: A review. Int. J. For. Res. 2014, 2014. [CrossRef]

22. Chambers, J.Q.; Asner, G.P.; Morton, D.C.; Anderson, L.O.; Saatchi, S.S.; Espírito-Santo, F.D.; Palace, M.; Souza, C. Regional ecosystem structure and function: Ecological insights from remote sensing of tropical forests. Trends Ecol. Evol. 2007, 22, 414-423. [CrossRef] [PubMed]

23. Mayes, M.T.; Mustard, J.F.; Melillo, J.M. Forest cover change in Miombo Woodlands: Modeling land cover of African dry tropical forests with linear spectral mixture analysis. Remote Sens. Environ. 2015, 165, $203-215$. [CrossRef]

24. Ernsta, C.; Verhegghena, A.; Bodartb, C.; Mayauxb, P.; de Wasseigec, C.; Bararwandikad, A.; Begotoe, G.; Mbaf, F.E.; Ibarag, M.; Shokoh, A.K. Congo basin forest cover change estimate for 1990, 2000 and 2005 by Landsat interpretation using an automated object-based processing chain. Int. Arch. Photogramm. Remote Sens. Spat. Inf. Sci. 2010, 38, 6.

25. Pahlevan, N.; Lee, Z.; Wei, J.; Schaaf, C.B.; Schott, J.R.; Berk, A. On-orbit radiometric characterization of OLI (Landsat-8) for applications in aquatic remote sensing. Remote Sens. Environ. 2014, 154, 272-284. [CrossRef]

26. Chander, G.; Markham, B.L.; Helder, D.L. Summary of current radiometric calibration coefficients for Landsat MSS, TM, ETM+, and EO-1 ALI sensors. Remote Sens. Environ. 2009, 113, 893-903. [CrossRef] 
27. Wu, M.; Wu, C.; Huang, W.; Niu, Z.; Wang, C.; Li, W.; Hao, P. An improved high spatial and temporal data fusion approach for combining Landsat and MODIS data to generate daily synthetic Landsat imagery. Inf. Fusion 2016, 31, 14-25. [CrossRef]

28. Zeng, C.; Shen, H.; Zhang, L. Recovering missing pixels for Landsat ETM + SLC-off imagery using multi-temporal regression analysis and a regularization method. Remote Sens. Environ. 2013, 131, 182-194. [CrossRef]

29. Poursanidis, D.; Chrysoulakis, N.; Mitraka, Z. Landsat 8 vs. Landsat 5: A comparison based on urban and peri-urban land cover mapping. Int. J. Appl. Earth Obs. Geoinf. 2015, 35 Part B, 259-269. [CrossRef]

30. Fassnacht, F.E.; Li, L.; Fritz, A. Mapping degraded grassland on the Eastern Tibetan Plateau with multi-temporal Landsat 8 data-where do the severely degraded areas occur? Int. J. Appl. Earth Obs. Geoinf. 2015, 42, 115-127. [CrossRef]

31. Irons, J.R.; Dwyer, J.L.; Barsi, J.A. The next Landsat satellite: The Landsat data continuity mission. Remote Sens. Environ. 2012, 122, 11-21. [CrossRef]

32. Spurr, S.H. Aerial photographs in forest management. Photogrammetria 1952, 9, 33-41. [CrossRef]

33. Shlien, S.; Smith, A. A rapid method to generate spectral theme classification of Landsat imagery. Remote Sens. Environ. 1975, 4, 67-77. [CrossRef]

34. France, M.J.; Hedges, P.D. A hydrological comparison of Landsat, TM, Landsat MSS and black and white aerial photography (North Wales). Remote Sens. Resour. Dev. Environ. Manag. 1986, 2, 717-720.

35. Venkataratnam, L. Use of remotely sensed data for soil mapping. J. Ind Soc. Photo-Interpret. Remote Sens. 1980, 8, 19-25.

36. Galmier, D.; Lacot, R. Photo interpretation, with examples of its usefulness. Photogrammetria 1970, 25, 131139-135146. [CrossRef]

37. Rao, D.P. Utility of Landsat coverage in small scale geomorphological mapping-some examples from India. J. Ind. Soc. Photo-Interpret. Remote Sens. 1978, 6, 49-56.

38. Schowengerdt, R.A. Techniques for Image Processing and Classifications in Remote Sensing; Academic Press: Cambridge, MA, USA, 2012.

39. Song, C.; Woodcock, C.E.; Seto, K.C.; Lenney, M.P.; Macomber, S.A. Classification and change detection using Landsat TM data: When and how to correct atmospheric effects? Remote Sens. Environ. 2001, 75, 230-244. [CrossRef]

40. Webster, R.; Wong, I.F.T. A numerical procedure for testing soil boundaries interpreted from air photographs. Photogrammetria 1969, 24, 59-72. [CrossRef]

41. Kirchhof, W.; Haberäcker, P.; Krauth, E.; Kritikos, G.; Winter, R. A rapid method to generate spectral theme classification of Landsat imagery. Acta Astronaut. 1980, 7, 243-253. [CrossRef]

42. Hardin, P.J. Neural networks versus nonparametric neighbor-based classifiers for semisupervised classification of Landsat Thematic Mapper imagery. Opt. Eng. 2000, 39, 1898-1908. [CrossRef]

43. Huang, C.; Davis, L.S.; Townshend, J.R.G. An assessment of support vector machines for land cover classification. Int. J. Remote Sens. 2002, 23, 725-749. [CrossRef]

44. Fisher, P.F.; Pathirana, S. The evaluation of fuzzy membership of land cover classes in the suburban zone. Remote Sens. Environ. 1990, 34, 121-132. [CrossRef]

45. Newman, M.E.; McLaren, K.P.; Wilson, B.S. Comparing the effects of classification techniques on landscape-level assessments: Pixel-based versus object-based classification. Int. J. Remote Sens. 2011, 32, 4055-4073. [CrossRef]

46. Zhou, W.; Troy, A.; Grove, M. Object-based land cover classification and change analysis in the Baltimore metropolitan area using multitemporal high resolution remote sensing data. Sensors 2008, 8, 1613-1636. [CrossRef] [PubMed]

47. Zhang, T.; Yang, X.; Hu, S.; Su, F. Extraction of coastline in aquaculture coast from multispectral remote sensing images: Object-based region growing integrating edge detection. Remote Sens. 2013, 5, 4470-4487. [CrossRef]

48. Hussain, M.; Chen, D.; Cheng, A.; Wei, H.; Stanley, D. Change detection from remotely sensed images: From pixel-based to object-based approaches. ISPRS J. Photogramm. Remote Sens. 2013, 80, 91-106. [CrossRef]

49. Sahai, B.; Dadhwal, V.K.; Chakraborty, M. Comparison of SPOT, TM and MSS data for agricultural land-use mapping in Gujarat (India). Acta Astronaut. 1989, 19, 505-511. [CrossRef] 
50. Duda, R.O.; Hart, P.E.; Stork, D.G. Pattern Classification and Scene Analysis Part 1: Pattern Classification; Wiley: Chichester, UK, 2000.

51. Fukue, K.; Shimoda, H.; Matumae, Y.; Yamaguchi, R.; Sakata, T. Evaluations of unsupervised methods for land-cover/use classifications of Landsat TM data. Geocarto Int. 1988, 3, 37-44. [CrossRef]

52. Miller, W.A.; Shasby, M.B. Refining Landsat classification results using digital terrain data. J. Appl. Photogr. Eng. 1982, 8, 35-40.

53. Ritter, N.D.; Hepner, G.F. Application of an artificial neural network to land-cover classification of Thematic Mapper imagery. Comput. Geosci. 1990, 16, 873-880. [CrossRef]

54. Townshend, J.R.; Justice, C.O. Unsupervised classification of MSS Landsat data for mapping spatially complex vegetation. Int. J. Remote Sens. 1980, 1, 105-120. [CrossRef]

55. Lunetta, R.S.; Ediriwickrema, J.; Johnson, D.M.; Lyon, J.G.; McKerrow, A. Impacts of vegetation dynamics on the identification of land-cover change in a biologically complex community in North Carolina, USA. Remote Sens. Environ. 2002, 82, 258-270. [CrossRef]

56. Rodriguez-Galiano, V.F.; Ghimire, B.; Rogan, J.; Chica-Olmo, M.; Rigol-Sanchez, J.P. An assessment of the effectiveness of a random forest classifier for land-cover classification. ISPRS J. Photogramm. Remote Sens. 2012, 67, 93-104. [CrossRef]

57. Swain, P.H.; Vardeman, S.B.; Tilton, J.C. Contextual classification of multispectral image data. Pattern Recognit. 1981, 13, 429-441. [CrossRef]

58. Tilton, J.C.; Swain, P.H. Contextual classification of multispectral image data. In Proceedings of the International Geoscience and Remote Sensing Symposium, Washington, DC, USA, 8-10 June 1981.

59. Magnussen, S.; Boudewyn, P.; Wulder, M. Contextual classification of Landsat TM images to forest inventory cover types. Int. J. Remote Sens. 2004, 25, 2421-2440. [CrossRef]

60. Liu, W.; Gopal, S.; Woodcock, C.E. Uncertainty and confidence in land cover classification using a hybrid classifier approach. Photogramm. Eng. Remote Sens. 2004, 70, 963-971. [CrossRef]

61. Simpson, J.J.; McIntire, T.J.; Sienko, M. An improved hybrid clustering algorithm for natural scenes. IEEE Trans. Geosci. Remote Sens. 2000, 38, 1016-1032. [CrossRef]

62. Warrender, C.E.; Augusteijn, M.F. Fusion of image classifications using Bayesian techniques with Markov random fields. Int. J. Remote Sens. 1999, 20, 1987-2002. [CrossRef]

63. Youngentob, K.N.; Roberts, D.A.; Held, A.A.; Dennison, P.E.; Jia, X.; Lindenmayer, D.B. Mapping two Eucalyptus subgenera using multiple endmember spectral mixture analysis and continuum-removed imaging spectrometry data. Remote Sens. Environ. 2011, 115, 1115-1128. [CrossRef]

64. Foody, G.; Cox, D. Sub-pixel land cover composition estimation using a linear mixture model and fuzzy membership functions. Remote Sens. 1994, 15, 619-631. [CrossRef]

65. Binaghi, E.; Brivio, P.A.; Ghezzi, P.; Rampini, A. A fuzzy set-based accuracy assessment of soft classification. Pattern Recognit. Lett. 1999, 20, 935-948. [CrossRef]

66. Somers, B.; Asner, G.P.; Tits, L.; Coppin, P. Endmember variability in spectral mixture analysis: A review. Remote Sens. Environ. 2011, 115, 1603-1616. [CrossRef]

67. Wang, L.; Shi, C.; Diao, C.; Ji, W.; Yin, D. A survey of methods incorporating spatial information in image classification and spectral unmixing. Int. J. Remote Sens. 2016, 37, 3870-3910. [CrossRef]

68. Mota, G.L.A.; Feitosa, R.Q.; Coutinho, H.L.C.; Liedtke, C.-E.; Müller, S.; Pakzad, K.; Meirelles, M.S.P. Multitemporal fuzzy classification model based on class transition possibilities. ISPRS J. Photogramm. Remote Sens. 2007, 62, 186-200. [CrossRef]

69. Wang, L. Fuzzy supervised classification of remote sensing images. IEEE Trans. Geosci. Remote Sens. 1990, 28, 194-201. [CrossRef]

70. Zhang, J.; Foody, G. A fuzzy classification of sub-urban land cover from remotely sensed imagery. Int. J Remote Sens. 1998, 19, 2721-2738. [CrossRef]

71. Melgani, F.; Al Hashemy, B.A.; Taha, S.M. An explicit fuzzy supervised classification method for multispectral remote sensing images. IEEE Trans. Geosci. Remote Sens. 2000, 38, 287-295. [CrossRef]

72. Ahmed, M.N.; Yamany, S.M.; Mohamed, N.; Farag, A.A.; Moriarty, T. A modified fuzzy c-means algorithm for bias field estimation and segmentation of MRI data. IEEE Trans. Med. Imaging 2002, 21, 193-199. [CrossRef] [PubMed]

73. Peterson, S.H.; Stow, D.A. Using multiple image endmember spectral mixture analysis to study chaparral regrowth in southern California. Int. J. Remote Sens. 2003, 24, 4481-4504. [CrossRef] 
74. Dawelbait, M.; Morari, F. Monitoring desertification in a Savannah region in Sudan using Landsat images and spectral mixture analysis. J. Arid Environ. 2012, 80, 45-55. [CrossRef]

75. Adams, J.B.; Sabol, D.E.; Kapos, V.; Almeida Filho, R.; Roberts, D.A.; Smith, M.O.; Gillespie, A.R. Classification of multispectral images based on fractions of endmembers: Application to land-cover change in the Brazilian Amazon. Remote Sens. Environ. 1995, 52, 137-154. [CrossRef]

76. Roberts, D.A.; Gardner, M.; Church, R.; Ustin, S.; Scheer, G.; Green, R.O. Mapping chaparral in the Santa Monica Mountains using multiple endmember spectral mixture models. Remote Sens. Environ. 1998, 65, 267-279. [CrossRef]

77. Powell, R.L.; Roberts, D.A.; Dennison, P.E.; Hess, L.L. Sub-pixel mapping of urban land cover using multiple endmember spectral mixture analysis: Manaus, Brazil. Remote Sens. Environ. 2007, 106, 253-267. [CrossRef]

78. Dorren, L.K.A.; Maier, B.; Seijmonsbergen, A.C. Improved Landsat-based forest mapping in steep mountainous terrain using object-based classification. For. Ecol. Manag. 2003, 183, 31-46. [CrossRef]

79. Peña, J.M.; Gutiérrez, P.A.; Hervás-Martínez, C.; Six, J.; Plant, R.E.; López-Granados, F. Object-based image classification of summer crops with machine learning methods. Remote Sens. 2014, 6, 5019-5041. [CrossRef]

80. Moskal, L.M.; Styers, D.M.; Halabisky, M. Monitoring urban tree cover using object-based image analysis and public domain remotely sensed data. Remote Sens. 2011, 3, 2243-2262. [CrossRef]

81. Kettig, R.L.; Landgrebe, D. Classification of multispectral image data by extraction and classification of homogeneous objects. IEEE Trans. Geosci. Electron. 1976, 14, 19-26. [CrossRef]

82. Flanders, D.; Hall-Beyer, M.; Pereverzoff, J. Preliminary evaluation of eCognition object-based software for cut block delineation and feature extraction. Can. J. Remote Sens. 2003, 29, 441-452. [CrossRef]

83. Trimble. Trimble acquires definiens' earth sciences business to expand its geospatial portfolio. In eCognition to Power Trimble's Image Analysis in Geospatial Industries; Trimble: Sunnyvale, CA, USA, 2010.

84. Samal, D.R.; Gedam, S.S. Monitoring land use changes associated with urbanization: An object based image analysis approach. Eur. J. Remote Sens. 2015, 48, 85-99. [CrossRef]

85. Li, Q.; Wang, C.; Zhang, B.; Lu, L. Object-based crop classification with Landsat-MODIS enhanced time-series data. Remote Sens. 2015, 7, 16091-16107. [CrossRef]

86. Kindu, M.; Schneider, T.; Teketay, D.; Knoke, T. Land use/land cover change analysis using object-based classification approach in Munessa-Shashemene landscape of the Ethiopian Highlands. Remote Sens. 2013, 5 , 2411-2435. [CrossRef]

87. Tewolde, M.G.; Cabral, P. Urban sprawl analysis and modeling in Asmara, Eritrea. Remote Sens. 2011, 3, 2148-2165. [CrossRef]

88. Wieland, M.; Pittore, M. Performance evaluation of machine learning algorithms for urban pattern recognition from multi-spectral satellite images. Remote Sens. 2014, 6, 2912-2939. [CrossRef]

89. Li, C.; Wang, J.; Wang, L.; Hu, L.; Gong, P. Comparison of classification algorithms and training sample sizes in urban land classification with Landsat Thematic Mapper imagery. Remote Sens. 2014, 6, 964-983. [CrossRef]

90. Gilbertson, J.K.; Kemp, J.; Van Niekerk, A. Effect of pan-sharpening multi-temporal Landsat 8 imagery for crop type differentiation using different classification techniques. Comput. Electron. Agric. 2017, 134, 151-159. [CrossRef]

91. Budreski, K.A.; Wynne, R.H.; Browder, J.O.; Campbell, J.B. Comparison of segment and pixel-based non-parametric land cover classification in the Brazilian Amazon using multitemporal Landsat TM/ETM+ imagery. Photogramm. Eng. Remote Sens. 2007, 73, 813-827. [CrossRef]

92. Vittek, M.; Brink, A.; Donnay, F.; Simonetti, D.; Desclée, B. Land cover change monitoring using Landsat MSS/TM satellite image data over West Africa between 1975 and 1990. Remote Sens. 2014, 6, 658-676. [CrossRef]

93. Böhner, J.; Selige, T.; Ringeler, A. Image segmentation using representativeness analysis and region growing. In SAGA-Analysis and Modelling Applications; Gottinger Geographischne Abhandlungen; Boehner, J., McCloy, K.R., Strobl, J., Eds.; Geographischne Abhandlungen: Gottingen, Germany, 2006; pp. 29-38.

94. Blaschke, T. Object based image analysis for remote sensing. ISPRS J. Photogramm. Remote Sens. 2010, 65, 2-16. [CrossRef]

95. Riggan, N., Jr.; Weih, R.C., Jr. Comparison of pixel-based versus object-based land use/land cover classification methodologies. J. Ark. Acad. Sci. 2009, 63, 145-152. 
96. Blundell, J.; Opitz, D. Object recognition and feature extraction from imagery: The Feature Analyst ${ }^{\circledR}$ approach. Int. Arch. Photogramm. Remote Sens. Spat. Inf. Sci. 2006, 36, C42.

97. Opitz, D.; Blundell, S. Object recognition and image segmentation: The Feature Analyst ${ }^{\circledR}$ approach. Object-Based Image Anal. 2008, 36, 153-167.

98. Tsai, Y.H.; Stow, D.; Weeks, J. Comparison of object-based image analysis approaches to mapping new buildings in Accra, Ghana using multi-temporal QuickBird satellite imagery. Remote Sens. 2011, 3, 2707-2726. [CrossRef]

99. Meinel, G.; Neubert, M. A comparison of segmentation programs for high resolution remote sensing data. Int. Arch. Photogramm. Remote Sens. 2004, 35, 1097-1105. [CrossRef]

100. Cai, S.; Liu, D. A comparison of object-based and contextual pixel-based classifications using high and medium spatial resolution images. Remote Sens. Lett. 2013, 4, 998-1007. [CrossRef]

101. Dingle Robertson, L.; King, D.J. Comparison of pixel- and object-based classification in land cover change mapping. Int. J. Remote Sens. 2011, 32, 1505-1529. [CrossRef]

102. Frohn, R.; Autrey, B.; Lane, C.; Reif, M. Segmentation and object-oriented classification of wetlands in a Karst Florida landscape using multi-season Landsat-7 ETM+ imagery. Int. J. Remote Sens. 2011, 32, 1471-1489. [CrossRef]

103. Zerrouki, N.; Bouchaffra, D. Pixel-based or object-based: Which approach is more appropriate for remote sensing image classification? In Proceedings of the 2014 IEEE International Conference on Systems, Man and Cybernetics (SMC), San Diego, CA, USA, 5-8 October 2014; IEEE: Piscataway, NJ, USA, 2014; pp. 864-869.

104. Huth, J.; Kuenzer, C.; Wehrmann, T.; Gebhardt, S.; Tuan, V.Q.; Dech, S. Land cover and land use classification with TWOPAC: Towards automated processing for pixel-and object-based image classification. Remote Sens. 2012, 4, 2530-2553. [CrossRef]

105. Liu, D.; Xia, F. Assessing object-based classification: Advantages and limitations. Remote Sens. Lett. 2010, 1, 187-194. [CrossRef]

106. Myint, S.W.; Gober, P.; Brazel, A.; Grossman-Clarke, S.; Weng, Q. Per-pixel vs. Object-based classification of urban land cover extraction using high spatial resolution imagery. Remote Sens. Environ. 2011, 115, 1145-1161. [CrossRef]

107. Darwish, A.; Leukert, K.; Reinhardt, W. Image Segmentation for the Purpose of Object-based Classification. In Proceedings of the 2003 IEEE International Conference on Geoscience and Remote Sensing Symposium, IGARSS'03, Toulouse, France, 21-25 July 2003; IEEE International: Piscataway, NJ, USA, 2003; pp. 2039-2041.

108. Möller, M.; Lymburner, L.; Volk, M. The comparison index: A tool for assessing the accuracy of image segmentation. Int. J. Appl. Earth Obs. Geoinf. 2007, 9, 311-321. [CrossRef]

109. Dronova, I.; Gong, P.; Clinton, N.E.; Wang, L.; Fu, W.; Qi, S.; Liu, Y. Landscape analysis of wetland plant functional types: The effects of image segmentation scale, vegetation classes and classification methods. Remote Sens. Environ. 2012, 127, 357-369. [CrossRef]

110. Drăguț, L.; Tiede, D.; Levick, S.R. ESP: A tool to estimate scale parameter for multiresolution image segmentation of remotely sensed data. Int. J. Geogr. Inf. Sci. 2010, 24, 859-871. [CrossRef]

111. Tailor, A.; Cross, A.; Hogg, D.C.; Mason, D.C. Knowledge-based interpretation of remotely sensed images. Image Vis. Comput. 1986, 4, 67-83. [CrossRef]

112. Sikder, I.U. Knowledge-based spatial decision support systems: An assessment of environmental adaptability of crops. Expert Syst. Appl. 2009, 36, 5341-5347. [CrossRef]

113. Wang, L.; Newkirk, R. A knowledge-based system for highway network extraction. IEEE Trans. Geosci. Remote Sens. 1988, 26, 525-531. [CrossRef]

114. Ghassemian, H. A review of remote sensing image fusion methods. Inf. Fusion 2016, 32 Part A, 75-89. [CrossRef]

115. Ehlers, M. Multisensor image fusion techniques in remote sensing. ISPRS J. Photogramm. Remote Sens. 1991, 46, 19-30. [CrossRef]

116. Hansen, M.; DeFries, R.; Townshend, J.R.; Sohlberg, R. Global land cover classification at $1 \mathrm{~km}$ spatial resolution using a classification tree approach. Int. J. Remote Sens. 2000, 21, 1331-1364. [CrossRef]

117. Otukei, J.R.; Blaschke, T.; Collins, M. Fusion of TerraSAR-X and Landsat ETM+ data for protected area mapping in Uganda. Int. J. Appl. Earth Obs. Geoinf. 2015, 38, 99-104. [CrossRef]

118. Carrão, H.; Gonçalves, P.; Caetano, M. Contribution of multispectral and multitemporal information from MODIS images to land cover classification. Remote Sens. Environ. 2008, 112, 986-997. [CrossRef] 
119. Hyde, P.; Dubayah, R.; Walker, W.; Blair, J.B.; Hofton, M.; Hunsaker, C. Mapping forest structure for wildlife habitat analysis using multi-sensor (LiDAR, SAR/inSAR, ETM+, QuickBird) synergy. Remote Sens. Environ. 2006, 102, 63-73. [CrossRef]

120. Xu, C.; Morgenroth, J.; Manley, B. Integrating data from discrete return airborne LiDAR and optical sensors to enhance the accuracy of forest description: A review. Curr. For. Rep. 2015, 1, 206-219. [CrossRef]

121. Hudak, A.T.; Lefsky, M.A.; Cohen, W.B.; Berterretche, M. Integration of LiDAR and Landsat ETM+ data for estimating and mapping forest canopy height. Remote Sens. Environ. 2002, 82, 397-416. [CrossRef]

122. Donoghue, D.N.M.; Watt, P.J. Using LiDAR to compare forest height estimates from IKONOS and Landsat $\mathrm{ETM}+$ data in Sitka spruce plantation forests. Int. J. Remote Sens. 2006, 27, 2161-2175. [CrossRef]

123. Hilker, T.; Wulder, M.A.; Coops, N.C.; Linke, J.; McDermid, G.; Masek, J.G.; Gao, F.; White, J.C. A new data fusion model for high spatial- and temporal-resolution mapping of forest disturbance based on Landsat and MODIS. Remote Sens. Environ. 2009, 113, 1613-1627. [CrossRef]

124. Pohl, C.; Van Genderen, J.L. Review article multisensor image fusion in remote sensing: Concepts, methods and applications. Int. J. Remote Sens. 1998, 19, 823-854. [CrossRef]

125. Toll, D.L. Effect of Landsat Thematic Mapper sensor parameters on land cover classification. Remote Sens. Environ. 1985, 17, 129-140. [CrossRef]

126. Haack, B.; Bryant, N.; Adams, S. An assessment of Landsat MSS and TM data for urban and near-urban land-cover digital classification. Remote Sens. Environ. 1987, 21, 201-213. [CrossRef]

127. Mulligan, P.J.; Gervin, J.C.; Lu, Y.C. Comparison of MSS and TM Data for Landcover Classification in the Chesapeake Bay Area-A Preliminary Report; NASA: Washington, DC, USA, 1985; pp. 415-419.

128. Heumann, B.W. An object-based classification of mangroves using a hybrid decision tree-Support vector machine approach. Remote Sens. 2011, 3, 2440-2460. [CrossRef]

129. Pullanikkatil, D.; Palamuleni, L.; Ruhiiga, T. Assessment of land use change in Likangala River catchment, Malawi: A remote sensing and DPSIR approach. Appl. Geogr. 2016, 71, 9-23. [CrossRef]

130. Sloan, S. Historical tropical successional forest cover mapped with Landsat MSS imagery. Int. J. Remote Sens. 2012, 33, 7902-7935. [CrossRef]

131. Kumar, R.; Nandy, S.; Agarwal, R.; Kushwaha, S.P.S. Forest cover dynamics analysis and prediction modeling using logistic regression model. Ecol. Indic. 2014, 45, 444-455. [CrossRef]

132. Vieira, I.C.G.; de Almeida, A.S.; Davidson, E.A.; Stone, T.A.; Reis de Carvalho, C.J.; Guerrero, J.B. Classifying successional forests using Landsat spectral properties and ecological characteristics in Eastern Amazônia. Remote Sens. Environ. 2003, 87, 470-481. [CrossRef]

133. Justice, C.; Townshend, J. A comparison of unsupervised classification procedures on Landsat MSS data for an area of complex surface conditions in Basilicata, Southern Italy. Remote Sens. Environ. 1982, 12, 407-420. [CrossRef]

134. Kirui, K.B.; Kairo, J.G.; Bosire, J.; Viergever, K.M.; Rudra, S.; Huxham, M.; Briers, R.A. Mapping of mangrove forest land cover change along the Kenya coastline using Landsat imagery. Ocean Coast. Manag. 2013, 83, 19-24. [CrossRef]

135. Lunetta, R.S.; Johnson, D.M.; Lyon, J.G.; Crotwell, J. Impacts of imagery temporal frequency on land-cover change detection monitoring. Remote Sens. Environ. 2004, 89, 444-454. [CrossRef]

136. Stuckens, J.; Coppin, P.R.; Bauer, M.E. Integrating contextual information with per-pixel classification for improved land cover classification. Remote Sens. Environ. 2000, 71, 282-296. [CrossRef]

137. Flygare, A. A comparison of contextual classification methods using Landsat TM. Int. J. Remote Sens. 1997, 18, 3835-3842. [CrossRef]

138. Lo, C.; Choi, J. A hybrid approach to urban land use/cover mapping using Landsat 7 Enhanced Thematic Mapper plus (ETM+) images. Int. J. Remote Sens. 2004, 25, 2687-2700. [CrossRef]

139. Kuemmerle, T.; Radeloff, V.C.; Perzanowski, K.; Hostert, P. Cross-border comparison of land cover and landscape pattern in Eastern Europe using a hybrid classification technique. Remote Sens. Environ. 2006, 103, 449-464. [CrossRef]

140. Hamada, Y.; Stow, D.A.; Roberts, D.A.; Franklin, J.; Kyriakidis, P.C. Assessing and monitoring semi-arid shrublands using object-based image analysis and multiple endmember spectral mixture analysis. Environ. Monit. Assess. 2013, 185, 3173-3190. [CrossRef] [PubMed] 
141. Théau, J.; Peddle, D.R.; Duguay, C.R. Mapping lichen in a caribou habitat of Northern Quebec, Canada, using an enhancement_classification method and spectral mixture analysis. Remote Sens. Environ. 2005, 94, 232-243. [CrossRef]

142. Ton, J.; Sticklen, J.; Jain, A.K. Knowledge-based segmentation of Landsat images. IEEE Trans. Geosci. Remote Sens. 1991, 29, 222-232. [CrossRef]

143. Manandhar, R.; Odeh, I.O.; Ancev, T. Improving the accuracy of land use and land cover classification of Landsat data using post-classification enhancement. Remote Sens. 2009, 1, 330-344. [CrossRef]

144. Shimoda, H.; Fukue, K.; Yamaguchi, R.; Zi-Jue, Z.; Sakata, T. Accuracy of landcover classification of TM and SPOT data. In Proceedings of the 1988 IEEE International Conference on Geoscience ang Remote Sensing Symposium, IGARSS'88, Edinburgh, UK, 10-12 September 1988; Volume 1, pp. 529-535.

145. Franklin, S.E. Topographic context of satellite spectral response. Comput. Geosci. 1990, 16, $1003-1010$. [CrossRef]

146. Huang, X.; Lu, Q.; Zhang, L.; Plaza, A. New postprocessing methods for remote sensing image classification: A systematic study. IEEE Trans. Geosci. Remote Sens. 2014, 52, 7140-7159. [CrossRef]

147. Tatem, A.J.; Nayar, A.; Hay, S.I. Scene selection and the use of NASA's global orthorectified Landsat dataset for land cover and land use change monitoring. Int. J. Remote Sens. 2006, 27, 3073-3078. [CrossRef] [PubMed]

148. Gutman, G.; Huang, C.; Chander, G.; Noojipady, P.; Masek, J.G. Assessment of the NASA-USGS global land survey (GLS) datasets. Remote Sens. Environ. 2013, 134, 249-265. [CrossRef]

149. Young, N.E.; Anderson, R.S.; Chignell, S.M.; Vorster, A.G.; Lawrence, R.; Evangelista, P.H. A survival guide to Landsat preprocessing. Ecology 2017, 98, 920-932. [CrossRef] [PubMed]

150. Tucker, C.J.; Grant, D.M.; Dykstra, J.D. NASA's global orthorectified Landsat data set. Photogramm. Eng. Remote Sens. 2004, 70, 313-322. [CrossRef]

151. Roy, D.P.; Wulder, M.A.; Loveland, T.R.; Woodcock, C.E.; Allen, R.G.; Anderson, M.C.; Helder, D.; Irons, J.R.; Johnson, D.M.; Kennedy, R.; et al. Landsat-8: Science and product vision for terrestrial global change research. Remote Sens. Environ. 2014, 145, 154-172. [CrossRef]

152. Franklin, S.E. Image transformations in mountainous terrain and the relationship to surface patterns. Comput. Geosci. 1991, 17, 1137-1149. [CrossRef]

153. Fahsi, A.; Tsegaye, T.; Tadesse, W.; Coleman, T. Incorporation of digital elevation models with Landsat-TM data to improve land cover classification accuracy. For. Ecol. Manag. 2000, 128, 57-64. [CrossRef]

154. Gao, Y.; Zhang, W. LULC classification and topographic correction of Landsat-7 ETM+ imagery in the Yangjia River Watershed: The influence of DEM resolution. Sensors 2009, 9, 1980-1995. [CrossRef] [PubMed]

155. Castillejo-González, I.L.; Peña-Barragán, J.M.; Jurado-Expósito, M.; Mesas-Carrascosa, F.J.; López-Granados, F. Evaluation of pixel- and object-based approaches for mapping wild oat (Avena sterilis) weed patches in wheat fields using QuickBird imagery for site-specific management. Eur. J. Agron. 2014, 59, 57-66. [CrossRef]

156. Araya, Y.H.; Cabral, P. Analysis and modeling of urban land cover change in Setúbal and Sesimbra, Portugal. Remote Sens. 2010, 2, 1549-1563. [CrossRef]

157. Dronova, I. Object-based image analysis in wetland research: A review. Remote Sens. 2015, 7, 6380-6413. [CrossRef]

(C) 2017 by the authors. Licensee MDPI, Basel, Switzerland. This article is an open access article distributed under the terms and conditions of the Creative Commons Attribution (CC BY) license (http://creativecommons.org/licenses/by/4.0/). 